\title{
Differences in Mean Number of Consonant-Vowel-Consonant Words Decoded between Letter-Sound Readers and Non Letter-Sound Readers
}

\author{
Gail M. Wolf \\ Oregon Health \& Science University, Portland, Oregon, USA \\ Email: wolfg@ohsu.edu \\ Received 19 February 2014; revised 25 April 2014; accepted 16 May 2014 \\ Copyright (C) 2014 by author and Scientific Research Publishing Inc. \\ This work is licensed under the Creative Commons Attribution International License (CC BY). \\ http://creativecommons.org/licenses/by/4.0/

(c) (i) Open Access

\begin{abstract}
Children's failure to develop simple word decoding skills in early years is linked to future poor reading, school dropout, and poor health [1] [2]. Letter-sound knowledge is needed for word decoding development; however questions remain on what types of letter-sound knowledge help children decode simple words [3]. This study investigated the differences in mean number of consonant-vowel-consonant (CVC) words decoded between two groups of children, a letter-sound reading group and non letter-sound reading group. Children aged 4 to 6 in both groups, attempted to decode a variety of simple words such as tan, sit, hen, pig, dot, and fun. Analysis determined word decoding differences existed between the two groups. The alternate hypothesis was accepted; the letter-sound reading group had a significantly higher mean in number of consonantvowel-consonant words decoded compared to the non letter-sound reading group. The study informs the teaching approaches needed to improve early decoding skills showing letter-sound reading ability is an important step for learning to decode simple consonant-vowel-consonant words.
\end{abstract}

\section{Keywords}

Letter-Sound Reading, Decoding, Automaticity, Practicing Reading

\section{Introduction}

\subsection{Introduction to the Problem}

The National Assessment of Educational Progress revealed that 37\% of US fourth graders fail to achieve basic

How to cite this paper: Wolf, G.M. (2014) Differences in Mean Number of Consonant-Vowel-Consonant Words Decoded between Letter-Sound Readers and Non Letter-Sound Readers. Open Journal of Nursing, 4, 409-450.

http://dx.doi.org/10.4236/ojn.2014.46047 
levels of reading [3]. Over 20\% of adults in the US read below a basic literacy level possessing only simple literacy skills such as signing and reading their name [4]. Only 13\% of adults read at or above proficient reading levels [4]. Poor literacy skills contribute to poverty and poor health [2]. Poor reading development in elementary school has been linked to later school failure, crime, long lasting poor reading into adulthood, and early mortality [3] [5].

Failure to develop basic decoding skills by first grade is predictive of lifelong poor literacy [3]. Unless early decoding skills move beyond mastery to become an automatic subconscious habit, reading is likely to remain poor [1] [6] [7]. Little progress has been made in discovering how decoding skills develop in the minds of young children [8] [9]. There are inconsistent data on what teaching practices foster simple word decoding development [3] [8].

\subsection{Background and Context for the Problem}

The topic of teaching children to read is at the forefront of reading research [10]. In the past, reading research centered on what were the best methods of teaching reading: whole word methods or phonics methods [11] [12]. In the nineties, Adams [1] complied and interpreted over 50 years of quantitative reading research. Adams succinctly described what skillful readers do: Do skilled readers predict words, guess, look at context, or see words as whole units? No. Rather it was poor readers who relied on whole word recognition, context, prediction, and guessing in order to read [1]. The decades of research proved that skillful readers visualize every single letter in every word then instantly clump the letters into the proper spelling-to-sound translation [1].

Another key finding from Adams's [1] book was that weakness in basic decoding skills was a root cause of lasting reading difficulties. The publication of Adams's seminal book sparked new shifts in reading research: how to help children learn to decode simple words so decoding can then be practiced and become automatic [8].

The National Reading Panel report [8] is a comprehensive review of reading research literature that influences how reading is taught in schools today [13]. The Panel members conducted an analysis of over 10,000 quantitative studies and the recommendations that followed were that children should a) learn to decode words early, b) repeat read text for effective decoding development, and c) practice decoding frequently so decoding becomes an automatic, subconscious habit.

However, information on what constitutes practicing decoding has been inconsistent [14]. The theory adopted by the National Reading Panel followed [15] repeat reading theory that repeated reading of the same text was a method of practicing rapid decoding [8]. Seminal work by Chomsky [16] also advocated for the repeat reading practice. However, Chomsky claimed repeat reading was not practicing decoding. Chomsky asserted repeat reading was a text-memorization process to help children who could not decode feel like a reader. Kuhn [17] and Therrien and Hughes [18] reported it was not repeat reading the same text, but practice in decoding a variety of new and different text that improved decoding skills.

Deeney [14], Eldredge [19] and Hicks [20] claimed repeat reading does not help children decode, rather it was practice in phonics, learning letter-sound correlations, which helped develop decoding skills. These aforementioned studies align with the National Reading Panel's report that letter-sound knowledge is needed to help children learn to decode [8]. What remained vague was a) what is meant by letter-sound knowledge, b) how should letter-sounds be taught, and c) when should letter-sounds be taught [3] [8] [21].

The National Early Literacy Panel conducted a meta-analysis of quantitative research on the development of early literacy skills needed by 4-and-5-year-olds [3]. The National Early Literacy Panel found three key methods for teaching children about letters and letter-sound relations. These three methods were a) letter naming, b) phonics, and c) phonemic awareness [3]. Like the National Reading Panel, the National Early Literacy Panel found it difficult to interpret the mass of research on letter-sound teaching strategies [3] [8]. This difficulty was because in the literature the following terms and concepts were used yet not clearly and consistently defined or described a) phonics, b) alphabet knowledge, c) letter knowledge, d) code-focus, e) concepts about print, f) phonemic awareness training, and g) letter-sound knowledge [3]. Thus while the National Reading Panel and National Early Literacy Panel recommend that children should learn about letter sounds and practice word decoding, there are no specifics or clear recommendations of exactly how this teaching and learning process should proceed.

\subsection{Theoretical Framework}

Two seminal automaticity theories from LaBerge and Samuels [7] [22] are foundations of reading instruction 
today [6] [13] [23]. An important aspect of both theories is that proficient readers have word decoding skills that have become automatic. For children to become skillful readers, the print-to-sound decoding process must be practiced and must move beyond mastery to become a subconscious, automatic habit [15] [22].

Both Logan's [7], and LaBerge and Samuels's [22] seminal automaticity theories indicate good readers visually attend to each letter in every word they read; then effortlessly, without conscious thought, good readers group the letters into the proper spelling-to-sound translation. For instance, proficient readers first see the individual letters l-i-g-h-t then instantly, almost simultaneously clump these letters into the proper spelling-patternto-sound translation /light/.

Logan [7], LaBerge and Samuels [22], and Samuels [15] were less consistent on a) how word decoding skills develop, b) what initial teaching strategies help children develop word decoding, and c) how decoding can be practiced. Logan postulated one instance of decoding a word can lead to automatic word decoding there on out. Samuels [15] stressed hours of decoding practice and repeat reading practice is needed to develop automatic word decoding skills.

Phonics theory became well accepted after publication of Chall's [11] seminal works Learning to Read: The Great Debate (The Report of the Commission on Reading), [24]. Phonics is often referred to as letter-sound knowledge [3] [8] and phonics instruction is defined as a group of strategies used to teach children about letters and the sounds letters represent [1] [3]. Phonics theory is still a foundation of reading instruction today [13]. The accepted elements of phonics theory are a) systematic phonics instruction is needed to help children gain word decoding skills, b) children should be taught letter-sounds are useful for reading, and c) letter-sound correlations should be taught early [1] [3] [8] [11].

One important category of phonics is systematic phonics instruction, which is the process of explicitly teaching children a specific set of letter-sound relations and having the children read text that provides practice in decoding these specific letters [8]. The two main types of systematic phonics instruction are synthetic phonics and analytic phonics [25].

\subsection{The Problem Statement}

Illiteracy and poor literacy is a growing educational and public health problem [2]. One root cause of poor literacy is failure to learn to automatically decode simple words at a young age [1] [6] [26]. Theories on phonics and developing automatic decoding skills are incomplete [3] [8] [21]. In addition, a main strategy to help children master decoding skills is repeat reading text, however there are inconsistent data on whether the technique is effective [8].

Phonics theory supports the idea that letter-sound knowledge is needed for word decoding [3]. However, there are inconsistent definitions of what constitutes phonics instruction [3] [27] [28]. The National Reading Panel's meta-analysis on phonics research could not make specific recommendations on phonics instruction because most researchers failed to describe the phonics interventions [21].

Current initial letter and letter-sound instruction includes teaching children to a) name letters, b) complete auditory tasks, listening for discrete sounds within a spoken word (phonemic awareness), and c) use pictures to learn letter-sounds [29]-[31]. These instructional strategies do not embody the print-to-sound process of decoding. Rather, many letter-sound teaching strategies recommended today employ a sound-to-print encoding process [3] [31] [32]. It was unknown if letter-sound reading, a print-to-sound decoding process, impacts consonant-vowel-consonant (CVC) word decoding. It was unknown if there were differences in number of CVC words decoded when comparing letter-sound readers to non letter-sound readers.

\subsection{Purpose of the Study}

The purpose of this quantitative descriptive study was to examine the relation between letter-sound reading ability and CVC words decoded in children aged 4-to-6, controlling for age and gender. This study attempted to determine whether a letter-sound reading group had a significantly higher mean in decoding 30 CVC test bank words (Appendix A) compared to a non letter-sound reading group. It was expected that the study would add insights on a) how letter-sound reading impacts word decoding ability, and b) what types of phonics or letter-sound instruction might be most helpful in producing efficient word decoding skills.

\subsection{Research Question and Hypotheses}

The research question that guided this study was: 
Is there a significant difference in mean number of CVC words decoded between letter-sound reading children when compared to non letter-sound-reading children?

The null hypothesis (H10) and alternative hypothesis (H1A) were:

H10: There will be no significant difference in mean number of CVC words decoded between letter-sound readers and non letter-sound readers.

H1A: There will be a significant difference in mean number of CVC words decoded between letter-sound readers and non letter-sound readers.

Each child looked at the 26 lowercase letter cards and was asked, "Do you know what sound this letter makes?” Children's knowledge and responses to the basic letter-sound correlations (Appendix B) were recorded. Each child was then asked to decode a test bank of $30 \mathrm{CVC}$ words (Appendix A). This study used moments of measures data collection process. Moments of measures process simply means documenting with pencil and paper whether decoding is accurate or inaccurate [14] [33] [34]. The accuracy of the participant's response was documented on a data collection sheet (Appendix C) using a pencil. The moments of measure process is used in Pacific Northwestern schools; using pencil and paper is familiar to children and least intrusive (G. Francis, personal communication, June 14, 2012).

The age and gender of participants was documented so later through statistical analysis these independent predictors were controlled. The 3-way analysis of variance (ANOVA) procedure examined the relation between numbers of CVC words decoded and letter-sound reading after controlling for age and gender.

\subsection{Rationale, Relevance, and Significance of the Study}

\subsubsection{Contributions to the Field of Beginning Reading Instruction}

This study offered quantitative data on how letter-sound reading knowledge impacts CVC word decoding ability to add to the body of information on beginning reading instruction. To learn to read, children need to learn about letter-sounds and must practice decoding [3] [8] [30]. Previous studies on decoding skills have addressed a) when to teach letter-sound units [3] [21] [35], b) types of letter-sound teaching strategies [8] [35], and c) types of letter-sound knowledge that foster decoding practice [8] but without consensus. This study addressed the small quantity of research with children aged 4-to-6 on the relation between letter-sound reading knowledge and the ability to decode CVC words.

\subsubsection{Advancing Scientific Knowledge}

The National Reading Panel's meta-analysis on systematic phonics instruction categorized literacy performance in six specific areas: reading, spelling, decoding, pseudo-word decoding, and comprehension and oral reading. The meta-analysis did not enter letter-sound knowledge into the meta-analysis database ([21], p. 401). The National Reading Panel report contains no quantitative data relating letter-sound reading to CVC word decoding. This letter-sound reading and word decoding study gathered data beyond letter-sound knowledge to determine if there was a relation between letter-sound reading knowledge and word decoding, closing the National Reading Panel's meta-analysis gap.

\subsubsection{Expanding on the Theory of Automaticity}

Reading automaticity is the ability to automatically decode print, to instantly respond to print with the proper sound translation [7] [22]. Letter-sound reading is also a print-to-sound decoding process. It may be that rather than an automatic letter naming response to print the automatic letter-sound reading response increases word decoding ability. According to reading researcher Dr. Ludo Verhoeven, research on the relation between letter knowledge and word decoding is highly relevant, and the sounding of letters (letter-sound reading) may be a critical factor in learning to read (Ludo Verhoeven, personal communication, June 15, 2012).

\section{Nature of the Study: Overview of Methodology}

The target population for this study was 4-to-6-year-old English-speaking children. The sample was 4-to-6-yearold English-speaking children selected from a preschool and day care setting.

\subsection{Research Design}

The propose of this quantitative descriptive study was to examine the relation between letter-sound reading and 
CVC word decoding in children aged 4-to-6 controlling for age and gender. The study used analysis of variance (ANOVA) data analysis.

Children were grouped as letter-sound readers if children could respond with the basic letter-sound translation (Appendix B) to at least 15 of the 26 letters of the alphabet; a 60\% or higher letter-sound reading competency response. Children were grouped as non letter-sound readers if they could respond with the basic letter-sound translation to 14 letters or less of the 26 letters; a less than $60 \%$ letter-sound reading response. After the letter-sound reading attempts, all children were asked to decode 30 CVC words (Appendix A).

\subsection{Data Collection}

Data were collected in a single session with each participant, and lasted approximately 5 minutes per participant. Children were shown lowercase letter cards with one letter on each card. All 26 letter cards were presented in random order (Appendix C). The participant was asked, “Can you tell me what sound this letter makes?” Using moments of measure process and pencil and paper, the oral responses were documented on a data documentation sheet as accurate or inaccurate (Appendix C). If a child offered a letter naming response there was a onetime corrective feedback. The corrective feedback was documented.

After the letter-sound reading documentation, children were shown the $30 \mathrm{CVC}$ words (Appendix A) examples are: tan, sit, hen, pig, dot, fun, cup, fed, mop, wag, zip, job, kid, van, bat, yum box, led. The decoding responses were documented as either a correct or incorrect decoding response. How many words each child correctly decoded were documented (Appendix C). Analysis of variance (ANOVA) was used to quantify the mean number of CVC words decoded comparing the letter-sound reading group to the non letter-sound reading group to determine if there was a significance difference in decoding numbers.

\section{Definition of Terms}

This section of the dissertation defines key terms used in this study.

\subsection{Analytic Phonics Instruction}

Analytic phonics instruction is a method of reading by rhyming or analogy, moving from whole-to-part, for instance seeing the word peak and then being able to read the word, beak [9] [36]. Analytic phonics instruction teaches children a letter-sound within the process of decoding words [9] [16] [37].

\subsection{Automaticity}

Automaticity is defined as the ability of a reader to decode print instantly without conscious thought or effort [1] [6] [7] [22].

\subsection{Basic Sound Translation}

Basic sound translation is defined as the most common, basic sound translation each single letter of the alphabet represents (Appendix B). Each of the 26 letters of the alphabet has one basic sound translation; the basic sound translation of each vowel is the short vowel sound [12] [30] [38]. A letter-sound is denoted in print by appearing between slash marks, /c/.

\subsection{Consonant-Vowel-Consonant Words}

Consonant-vowel-consonant (CVC) words represent the simplest spelling pattern in the written English language [1] [12] [26]. CVC words contain only basic letter-sound translations. The vowel sounds are always short as in cat, hen, tip, log, and bus. Although there are about $250 \mathrm{CVC}$ words, all the words are comprised of one spelling pattern, the CVC pattern.

\subsection{Decoding and Word Decoding}

Decoding is defined as the ability to look at print and orally or silently respond with the proper sound translation; decoding is a print-to-sound process [1] [26] [38]. For instance a child looks at the word hen and orally says, 
"hen". A single letter can be decoded by looking at the letter and orally responding with the basic sound translation [39]. In this study, decoding a single letter is termed letter-sound reading.

\subsection{Decoding Practice}

Decoding practice is defined as practicing blending sounds into simple CVC words [1] [3]. Decoding practice is defined as the process of identifying letters and grouping the letters into the proper spelling-pattern-to-sound translation [1].

\subsection{Encoding}

Encoding is a sound-to-print process of listening for, hearing, and distinguishing a letter-sound and then finding the correct corresponding letter form [3] [40]. For instance a teacher says $/ \mathrm{m} /$ and the children correctly point to the letter symbol $m$. Encoding is often called receptive phonics, a sound-to-print process [38] [41].

\subsection{Fluency}

Fluency is defined as fast, accurate oral reading [1] [6] [8] [42] [43]. Gaining automatic decoding skills leads to fluent oral reading [1] [6] [42].

\subsection{Letter Naming}

Letter naming is defined as the ability to look at a lowercase or uppercase letter and orally respond with the letter name [1] [29]. A letter name is denoted in print by appearing in italics, $c$.

\subsection{Letter-Sound Knowledge}

Letter-sound knowledge is defined as knowledge about letters and the sounds the letters represent [3]. Letter-sound knowledge is often referred to as phonics [3].

\subsection{Letter-Sound Reading}

Letter-sound reading is defined as the ability to look at a lowercase letter and orally respond with the basic sound translation (Appendix B). Letter-sound reading is a print-to-sound translation process, thus letter-sound reading is the process of decoding a letter or reading a single letter [26] [39].

\subsection{Letter-Sound Reader}

A child was grouped as a letter-sound reader if he or she could give the correct, basic letter-sound response (Appendix B) to at least 60\% (15 of 26) of the lowercase letters.

\subsection{Moments of Measure}

Moments of measure is defined as a data collection procedure in which the accuracy of decoding print is recorded [14] [33] [34].

\subsection{Non Letter-Sound Reading}

Non letter-sound reading is defined as looking at a single, lower case letter and not responding with the correct basic letter-sound translation.

\subsection{Non Letter-Sound Reader}

A child was grouped as a non letter-sound reader if he or she could give the correct, basic letter-sound response (Appendix B) to 14 or less of the 26 lower case letters; a less than $60 \%$ letter-sound reading response.

\subsection{Phonemic Awareness}

Phonemic awareness (PA) is defined as the ability to focus on and manipulate phonemes in spoken words [8]. 
For instance, a child listens to and hears the spoken word "cat" and deciphers the word cat is made up of three distinct sounds, /c/, /a/, and /t/ [8].

\subsection{Phonics}

Phonics is defined as knowledge about letters and the sounds letters represent [3] [8]. Phonics is often referred to as letter-sound knowledge [3] [8].

\subsection{Phonics Instruction}

Phonics instruction is defined as strategies used to teach children about letters and the sounds letters represent [1] [3]. Categories of phonics instruction are systematic phonics, synthetic phonics, analytic phonics, receptive phonics, and productive phonics instruction [3]. Phonics instruction is often referred to as letter-sound instruction [3] [8].

\subsection{Productive Phonics Instruction}

Productive phonics instruction employs a print-to-sound decoding process [38].

\subsection{Reading}

Reading is defined as the ability to independently look at print, respond with the proper sound translation and comprehend the meaning of the print [1] [8]. Reading is the ability to independently decode print and comprehend print and is a print-to-sound translation process [1] [13] [29] [44].

\subsection{Receptive Phonics Instruction}

Receptive phonics instruction employs a sound-to-print teaching and learning process [38].

\subsection{Repeat Reading}

Repeat reading is a common reading instruction strategy in which a child reads the exact same text over and over until the oral reading becomes fluent [8] [14] [15] [20] [42].

\subsection{Synthetic Phonics Instruction}

Synthetic phonics instruction is a method of helping children sound out a word, blending individual lettersounds into a word [16] [28] [36].

\subsection{Systematic Phonics Instruction}

Systematic phonics instruction is the process of explicitly teaching children a specific set of letter-sound relations and having the children read text that provides practice in decoding these specific letters [8].

\subsection{Variables}

The independent variable in this study was letter-sound reading ability, the ability to look at a single, lowercase letter and verbally respond with the basic sound translation. This variable was dichotomized into letter-sound readers and non letter-sound readers.

The dependent variable was oral independent and accurate CVC word decoding. For example, the child who looked at the word zap and orally responded "zap" was word decoding. This variable was operationalized as a count of how many words were decoded from the $30 \mathrm{CVC}$ word test bank (Appendix A). Accurately decoding a word did not mean there was reading comprehension.

\section{Assumptions, Limitations, and Delimitations}

This study contained the following assumptions: 
1) The sample of the 4-to-6-year-old participants who attend preschools and day cares are children learning about letters, letter-sounds, and reading.

2) The majority of text that all people read is comprised of lowercase letter forms.

This study contained the following limitations:

1) The sample of children may not offer study results that will generalize to the target population of all young children learning to read.

2) Because data were collected at one time the results may not be a reflection of the participant's true ability.

3) Because this was an observational study not an experiment, the possibility that there were other important variables that were not measured cannot be ruled out.

This study contained the following delimitations:

1) The scope and boundary of this proposed study was to look at the relation between letter-sound reading skill and word decoding skill. There was not an investigation of CVC word comprehension. Because word decoding must occur before reading comprehension takes place [1] [6] this study looked only at decoding process.

2) The scope and boundary of the study was to quantify the relation between single letter-sound reading and CVC word decoding skill. There was not a way to determine if participants who correctly decoded a word were actually decoding the word or rote-recognizing the word. To decrease the delimitation, 30 simple CVC words (Appendix A) offered different letters in different positions to foster a decoding rather than rote-recognition process.

\section{Organization of the Remainder of the Study}

Chapter 1 of this dissertation described the reading research topic, the theoretical framework, problem statement, purpose, and the significance of the study. It has been established that gaining word decoding skills, then gaining automatic word decoding skills is a main goal of reading instruction [6] [8] [26]. It has been established that letter-sound knowledge enhances word decoding skills yet there is inconsistency in literature on a) what letter-sound knowledge (or phonics) really means, b) what types of letter-sound instruction should occur, and c) when letter-sound instruction should occur to best increase word decoding skills [3] [21] [35].

Chapter 2 is a comprehensive literature review in the arena of beginning reading instruction research. Chapter 2 reviews reading research in the areas of a) automaticity theory b) repeat reading teaching strategies to foster word decoding, c) approaches to teaching letter sounds (phonics), d) descriptive studies on growth of word decoding, e) methodological literature, f) seminal comprehensive reading research reports, and g) a chapter summary of key points. Chapter 3 details this study's research methodology, sampling procedures, data collection and data analysis. Chapter 4 presents the data results and statistical analysis of the data results. Chapter 5 presents interpretations of the data results including a discussion of implications for practice and future research.

\section{Literature Review}

\subsection{Introduction to the Literature Review}

The purpose of this literature review is to gain an appreciation of the current state of knowledge on beginning reading instruction. The main topics to be reviewed are a) automaticity theory, b) repeat reading theory and repeat reading strategies to develop children's decoding skills, c) letter-sound theory and teaching strategies, d) decoding skills, e) methodological literature, and f) seminal publications that have impacted the trajectory of reading instruction. A summary identifies gaps in reading research and shows why the study on letter-sound reading and word decoding was needed.

\subsection{Theoretical Framework: Automaticity Theory}

Automaticity theory has been studied in many fields and has the same underlying meaning: a skill has been practiced enough that the skill no longer requires conscious thought or effort. The skill is done quickly and accurately. The mind is free to attend to other input [1] [6] [7] [12] [22] [45].

Reading automaticity means accurate, fast, effortless word decoding: the ability of a reader to look at print and instantly respond with the proper sound translation, a print-to-sound process [6] [7] [22]. Gaining automatic 
word decoding ability (automaticity) is a prerequisite to becoming a proficient reader [1] [6] [8]. Failure to develop basic decoding skills in first grade contributes to failure to develop automatic decoding skills [1] [6] [8] [26] [29] [43].

Automatic word decoding skill is linked to reading comprehension. When a reader does not have to consciously think about decoding text, the reader's mind is free to comprehend text [1] [6] [8] [44]. Therefore, one root cause of poor reading comprehension is lack of automatic word decoding skill [1] [6] [7] [22] [24]. When a reader struggles with word decoding, the mind is not free to comprehend what is being read [1] [6] [8]. A main goal of reading instruction is to help children acquire automatic word decoding ability [1] [14] [38].

\subsection{Two Seminal Theories on Developing Reading Automaticity}

Logan's [7] instance theory of automatization has gained attention in the reading research world [8] [23]. Logan claims that each time a beginning reader decodes a word, an algorithm type memory trace is formed that will later be retrieved. Logan hypothesized that as decoding becomes automatic the algorithm track is dropped, previously learned decoding steps are skipped, and then abandoned entirely [7].

In his instance theory, Logan [7] claims one instance of decoding a word may be all that is needed to gain automaticity from that point forward. This theory may help explain why some children, who are no longer beginning readers, can be told, "This new word is bank", and the children can instantly and effortless read the following new words: Hank, rank, sank, tank, blank, clank, spank, crank, drank, Frank (C. Hudson, personal communication, December, 20, 2010).

LaBerge and Samuels's [22] reading automaticity theory differs from Logan's [7] theory in that LaBerge and Samuels reported reading automaticity is not a matter of skipping steps, but rather the steps move beyond mastery to become automatic [22]. The steps are a) distinguishing letters, b) grouping the letters into the proper spelling-pattern-to-sound translation (decoding), and c) grouping words into clusters to comprehend the text [22].

Furthering his work on automaticity theory, Samuels (1985) contended that automatic word decoding is a sub-skill which must first be mastered before fluent oral reading can occur. In short, automatic word decoding leads to fluent reading [15] [22] [42]. In contrast to Logan's [7] instance theory, LaBerge and Samuels's and Samuels's [15] theory stressed the need for many hours of word decoding practice; the practicing leads to automatic decoding skill [15] [22] [42]. Samuels [15] asserted repeat reading the same text to fluency helped develop rapid word decoding skills.

Blessing and Anderson [45] reviewed three automaticity theories: chunking, Adaptive Control of ThoughtRational Theory (ACT-RT) and Logan's instance theory. The ACT-RT theory of automatization aligns with LaBerge and Samuels' theory [45] [46]. Blessing and Anderson provided a compelling argument against Logan's step-skipping hypothesis that relates decoding to an algorithm process. Blessing and Anderson advise a certain truth: "Step skipping is not possible, or simply is not done, in all tasks" ([45], p. 593). For example, an adult automatically ties his or her shoes without thought; the process, now automatic, still requires the same steps. Blessing and Anderson deduced reading automaticity is not a matter of learning to skip steps but one of having practiced the steps. The practiced steps become faster and finally evolve into a subconscious habit [45].

The National Reading Panel is the collective voice of reading researchers who influence how reading is taught [8]. The National Reading Panel recognizes the worth of both Logan's [7] instance theory and LaBerge and Samuels's [22] automaticity theory noting how both theories highlight the need for independent, accurate, fast and effortless word decoding [8]. The National Reading Panel recognizes that both theories stress automatic word decoding is needed for reading comprehension. Importantly, automatic decoding ability is a process in which the reader visually attends to each individual letter in every word, and then almost simultaneously the individual letters are clumped into the proper spelling-to-sound translation [7] [8] [22].

The National Reading Panel mirrors Blessing and Anderson's [45] tendency to support LaBerge and Samuels's [22] theory over Logan's [7] with a cautionary note about Logan's theory: “...he [Logan] fails to emphasize the importance of practice or repetition within his description" [description of developing automaticity] ([8] pp. 3-7). The National Reading Panel implicitly offers more support for Samuels's [15] theory in the Panel's recommendation for children to develop word decoding skills through repeat reading activities [8].

\subsection{Synthesis of Automaticity Theory Literature}

Automatic word decoding is independent, effortless, accurate, and fast; to develop automatic word decoding, 
word decoding must be practiced [1] [6] [15] [26]. Attention to every letter in every word is an important component of word decoding development [1] [15]. Beginning reading instruction should have a main goal of helping children first learn to decode print, so they can then practice decoding [1] [6] [22].

\subsection{Critique of Automaticity Theory Literature and Need for Current Study}

There continue to be gaps in automaticity theory. There is little information on how children first learn to decode print so decoding can then be practiced. Automaticity theory does not answer certain questions a) How do beginning readers first decode a word, and b) What knowledge and instruction is needed to help children practice word decoding so the skill can become automatic? Logan [7] postulated that one instance of seeing and decoding a word in print can create automatic decoding from that point on. However, Logan did not explain how the first instance of word decoding takes place.

Samuels asserted that decoding must be extensively practiced; he promoted repeat reading teaching strategies [6] [8] [15]. Samuels postulated that repeat reading the same text over and over to fluency is a way to practice rapid decoding [8] [15]. However, Chomsky's [16] work on repeat reading suggested that repeat reading strategies do not foster attention to letters and decoding processes; instead repeat reading strategies foster rote-memorization of text.

There are inconsistent data on how basic decoding skills should be taught to children who are just beginning to read. Also data are inconsistent on whether repeat reading strategies foster word decoding or foster text memorization [14] [16]. The inconsistencies beg for a closer look at the repeat reading theories and instructional strategies.

\section{Repeat Reading Teaching Strategies to Develop Word Decoding Skills}

Repeat reading is defined as oral reading of the same paragraph or text over and over until reading is fluent, fast and accurate [8] [14] [15] [20] [42]. A complex theory, repeat reading begins with consistent data that poor decoding skills are a root cause of poor reading comprehension [1] [8] [15] [26]. Thus a main way to improve children's reading comprehension is to improve children's decoding skills [1] [8] [26]. In today's schools, repeat reading is a strategy used to improve decoding skills [14] [20]; (G. Francis, personal communications, August 8, 2012).

Repeat reading theory has origins in Samuels's automaticity theory [8] [15]. Samuels theorized if children repeat read the same text to fluency the children will gain automatic decoding skills [15] [42] [46] [47]. Samuels [15] [42] asserted repeat reading is a process of practicing rapid decoding. Most importantly, Samuels wrote, "We assume that, because of the extensive practice on rapid recognition of these words, the words are decoded automatically” ([15] p. 228).

These are the main four repeat reading teaching strategies a) children read after a teacher (echo reading), b) children read with a tape recorded voice reading the text, c) children choral read with entire class, and d) children repeat read text independently [1] [8] [48]-[51].

\subsection{Chomsky's Repeat Reading Theory}

As Samuels was testing his repeat reading theory to help children develop automatic decoding skills, Carol Chomsky at Berkeley was developing and using the exact same repeat reading methods [16]. Chomsky reported repeat reading increased overall reading success, but reported that the repeat reading technique helps children who cannot decode, memorize text [16]. Chomsky's works do not deduce that repeat reading helps develop decoding skills, but rather repeat reading helps children memorize text to develop a sense of decoding success [16]. The title of Chomsky's work “After decoding, What?” points to the dichotomy in the repeat reading theories. Chomsky asserted text memorization through repeat reading techniques does help third graders, who cannot decode, become more confident in reading abilities [16].

The research on repeat reading is important because repeat reading is a main instructional strategy used in schools today to develop children's word decoding skills [8] [14]. The National Reading Panel supports Samuels's [15] four repeat reading assumptions a) repeat reading is not text memorization but a method of practicing decoding; b) repeat reading helps children develop rapid decoding skills; c) automatic decoding skills lead to 
fluent reading; d) because repeat reading improves decoding skills, children’s reading comprehension will also improve [8].

The National Reading Panel examined 14 studies on repeat reading which led to the recommendation of using repeat reading techniques in schools [8].

Many of these studies are reviewed below.

\subsection{The Repeat Reading Studies}

The early studies on repeat reading [48]-[54] used repeat reading techniques a) echo reading, b) reading with a tape recorded voice, c) choral reading, and d) independent repeat reading. The researchers used a sample selection range of third graders to sixth graders. Moments of measure data collection methods were used in the studies: correct words read per minute (cwpm) or correct words read per reading session were documented [48]-[54]. In moments of measure data collection, children are asked to decode a list of words and a check mark is placed next to the words accurately decoded (G. Francis, personal communications, September 10, 2011).

Two studies found that although repeat reading techniques may improve children's reading fluency, repeated reading interventions did not correlate to improved reading comprehension [15] [52]. However, the majority of the early studies found repeat reading the same text to fluency helped children improve decoding, and ultimately children's reading comprehension of the specific text repeatedly read [48]-[54]. One study showed an increase in reading comprehension when students were asked to pay attention to what they were reading [53].

The following studies reported that poor readers did increase oral reading fluency of the specific text which was repeatedly read [48]-[51] [53] [54]. However, there were no quantitative data showing repeat reading techniques increased word decoding of new text [8]. The National Reading Panel pointed out the aforementioned repeat reading studies did not fail to find transfers of decoding skills to new text, the studies did not attempt to measure decoding transfer skills ([8] pp. 3-15). The early studies laid a foundation for future repeat reading studies.

Musti-Rao, Hawkins, and Barkley [55] reported limited gains in reading comprehension with repeat reading; the technique of repeat reading the same text to fluency was recommended. Schwanenflugel's [43] study showed no gains in reading comprehension with repeat reading, thus questioned if repeat reading improves word decoding.

In the following studies participants were asked to repeat read a specific text until fluent; then children were asked to repeat read different text as well [14] [17] [18] [20] [34]. The aforementioned researchers reported the following conclusions a) repeat reading did not increase reading comprehension, b) repeat reading may be hindering reading comprehension, and c) repeat reading may increase reading speed and fluency of the repeated paragraph, but did not increase children's reading comprehension [14] [17] [18] [20] [34]. Kuhn [17] and Therrien and Hughes [18] found repeat reading using different text increases reading comprehension more than repeat reading the same text.

\subsection{Repeat Reading, Phonics Skills, and Word Decoding}

Deeney [14] Eldredge [19] and Hicks [20] noted that students who struggled the most with repeat reading, continued to display poor decoding skills; these researchers recommended that phonics should be taught to improve word decoding. Schwanenflugel [43] also concluded that practice with letter-sounds, not repeat reading, improved decoding and led to fluent reading. These results mirror other studies which concluded weakness in basic decoding skills and failure of young readers to attend to all letters when decoding words are root causes of later poor reading [1] [56].

\subsection{A Synthesis of Repeat Reading Research}

Repeat reading research is consistent in moments of measure procedure [14] [17] [18] [20] [43] [55]. The moments of measure procedure is considered a valid and reliable tool to measure decoding accuracy because of the simplicity of the procedure, placing a check mark next to words accurately decoded [33]. Moments of measure data collection methods were used in the following repeat reading studies to record accuracy of decoding and speed of decoding [15] [43] [52] [55]. 
Along with consensus on data collection methodology there are at least three other consistencies among repeat reading researchers:

1) Poor or slow decoding skills are a root cause of poor reading comprehension. When a reader has to concentrate on decoding, the mind is not free to comprehend the text [1] [6]-[8] [13] [22]-[24].

2) Automatic decoding ability is the precursor to fluent (oral) reading ability. Fluent reading means effortless, fast, accurate oral reading [1] [6]-[8] [13] [22].

3) Most researchers reported the ultimate purpose of repeat reading the same text to fluency is to develop automatic decoding skills to improve reading comprehension [1] [6]-[8] [14] [15] [17] [20] [22] [42].

The above points end the consistency in repeat reading research and dispute begins. Two underlying theories support the repeat reading text to fluency teaching strategy. Samuels's [15] theory is that repeat reading results in development of rapid decoding. Chomsky's [16] theory is that repeat reading helps children with poor decoding skills memorize text because trying to decode text is not working. The National Reading Panel supports Samuels's theory that repeat reading helps develop word decoding skills [8]. Others reported that repeat reading to fluency techniques did not foster word decoding ability [14] [17] [18] [20] [34].

Deeney [14], Eldredge [19] and Hicks [20] had four reservations about the repeat reading the same text to fluency technique a) there is not enough evidence that repeat reading the same text to fluency helps a student become an independent or autonomous reader in decoding of new text, b) teachers are stressing speed of reading over accuracy, c) moments of measure fluency tests are not assessing reading comprehension, d) repeat reading the same text to fluency is not correlated to increased reading comprehension.

\subsection{Critique of the Repeat Reading Research}

Regardless of the inconsistent research results, repeat reading is a teaching strategy used in schools to improve word decoding and reading comprehension [6] [8] [14] [17] [18] [20] [34] [43] [55]. However, some research found repeat reading the same text to fluency does not help beginning readers attend to all letters to improve decoding skills, the very skill needed for improved reading comprehension. It may be Samuels's [15] long ago assumption, which is accepted by the National Reading Panel, that repeat reading builds rapid word decoding skills is incorrect. It may be that Chomsky's [16] repeat reading theory is more correct: Repeat reading fosters, not decoding, but text memorization.

\subsection{Need for Current Study}

Some data support the view that phonics skills and simple word decoding skills must be ingrained during beginning reading instruction; otherwise later reading fluency cannot be attained through repeat reading strategies [15] [26] [43] [52]. This new study has laid a foundation examining the relationship between letter-sound reading and CVC word decoding and will be valuable to later repeat reading studies. Possibly letter-sound readers might attend to all letters in words as skillful readers do, thus as Samuels [15] postulated, letter-sound readers may tend to truly repeatedly rapidly decode text rather than tend to memorize text.

Research points to the need for children to acquire letter-sound knowledge to become skillful word decoders [1] [8] [32]. Therefore the next section reviews literature on letter and letter-sound teaching strategies.

\section{Research on Letter and Letter-Sound Teaching Strategies}

First steps towards literacy often involve teaching children about individual letters and the sounds the letters represent [3] [32] [57]. These first steps involve a) letter naming, b) phonics, and c) phonemic awareness approaches [8] [29] [58]. This literature review section presents data on these three main beginning reading approaches.

\subsection{Letter Naming Instruction}

Letter name knowledge is the ability to look at a letter and respond with the letter name [8]. In the United States letter name instruction remains a first step in teaching children to read [1] [8] [29] [58]. State curriculum standards throughout the nation require children to look at letters, often starting with capitals, to learn to name letters [59]. Research on letter naming ability and the relation to word decoding is of interest. 
There have been studies checking the relation between letter naming skills to decoding development [1] [60]-[62]. Results of most letter naming studies showed little association between letter naming and word decoding skills [1] [3] [8] [62].

Even though letter naming skill does not relate to word decoding, letter naming remains a recommended first step in learning to read [1] [29] [31]. For this recommendation, researchers offer these five rationale a) letter naming is a tradition, b) letters need a label, c) it is easier to look at a letter and respond with a letter name than a letter-sound, d) letter names help children with spelling, and e) naming letters can help children learn some letter-sounds [1] [29]. However, empirical data show that letter-sound knowledge has a higher relation to word decoding [3] [8]. Therefore, a review of letter-sound instruction, often called phonics instruction is important.

\subsection{Phonics Instruction}

Phonics instruction is a broad term meaning to teach children letter-sound relationships [21] [63]. The National Reading Panel's meta-analysis of phonics research reported children need letter-sound knowledge to learn to decode print [8]. The National Reading Panel further maintained systematic phonics instruction is needed. Systematic phonics instruction is the process of explicitly teaching children a specific set of letter-sound relations and having the children read text that provides practice in decoding these specific letters [8].

There are two main systematic phonics instruction strategies: synthetic phonics instruction and analytic phonics instruction [41] [63]. Synthetic phonics is a method of helping children sound out a word, blending individual sounds into words [25] [28] [36]. Analytic letter-sound instruction is a method of reading by rhyming or analogy, or moving from whole-to-part, for instance learning to read the word peak and then being able to read the word beak [25] [28] [36]. Analytic letter-sound instruction teaches children a letter-sound within the process of reading words [9] [25] [37].

Phonics researchers have been criticized for not describing the method of teaching children about letter-sound relations [21] [64] [65]. Despite this failing, there are some studies, discussed below, which offer moderate descriptions of letter-sound teaching strategies. Rather than analytic or synthetic phonics, the described interventions most often fall into categories of receptive phonics and productive phonics instruction.

\subsection{Receptive Phonics and Productive Phonics Instruction}

A primary receptive phonics teaching strategy engages the learner in looking at a picture, for instance a picture of a cat, then circling the appropriate letter $c$ associated with the first sound heard when orally verbalizing "cat" [30] [31], (G. Francis, personal communication, August 8, 2012). Many phonics approaches engage children in this type of receptive sound-to-print process which includes the use of pictures [30] [66].

Walton and Walton [41] also used receptive phonics in their teaching. They used a large mat with letters, much like the Twister game mat [41]. The teacher would orally verbalize a sound/m/and have children jump to the letter $m$ on the mat that matched the verbalized sound. This employed the sound-to-print receptive phonics process. Other phonics strategies used objects, hand-motions, and puppets to help instill letter-sound knowledge [41]. Walton and Walton's study concluded that explicit teaching of letter-sounds was more effective than implicit strategies in helping children identify a letter within a simple CVC word.

Christensen and Bowey [40] taught phonics to two groups of 7-year-old children with a third control group. The researchers wanted to see if two types of phonics instruction strategies might create a statistically significant difference in a 55 word reading test. The two intervention groups received an explicit type of phonics instruction. Both described letter-sound teaching strategies used a receptive sound-to-print process [40]. One instruction method introduced students to six words, which were repeatedly read as a group with the teacher's help, and then the children read the words to the teacher. Christensen and Bowey reported, "This provided extended practice in decoding the words" ([40], p. 336). The other group's instruction was helping children locate words that contained a specific letter-sound correspondence that was being studied. For instance, if the letter being studied was $p$, the children would look for words which contained the letter. The results of the study showed that children in the explicit letter-sound teaching groups had higher reading scores over the control group, which did not have explicit phonics instruction [40].

Some researchers found the sound-to-print receptive letter-sound training helps children spell [38]. Productive letter-sound training, a print-to-sound process, helps children read [38]. Verhoeven and Leeuwe's [26] study employed a productive print-to-sound phonics teaching process. Dutch children from the onset of literacy in- 
struction learn letter-sounds; they learn to look at letters and respond with the basic sound translation using productive phonics method (L. Verhoeven, personal communication, March 23, 2011). Verhoeven and Leeuwe's study used a sample of 2819 Dutch children. The study results showed Dutch kindergarten children who were most skilled at blending single letter-sounds into CVC words were the better readers in sixth grade [26].

Research by Comaskey [25] is notable because Comaskey quantified differences in decoding skill by comparing a synthetic phonics instruction group with an analytic phonics instruction group. While there were no descriptions of how children were taught letter-sound correspondences, there was no statistically significant difference between the two groups' decoding skills.

Denton and Otaiba [35] studied the impact of the same systematic phonics instruction for two groups of children, learning disabled and non learning disabled. The study results were that both groups improved in word decoding after systematic phonics instruction [35]. How letter-sound relations were taught to children was not described. The researchers recommended letter-sounds should be taught in an organized, sequenced fashion and that children should be given daily opportunities to respond to text [35].

\subsection{Synthesis of Phonics Research Instruction}

Consensus among past phonics researchers is clear, letter-sound relations (phonics), should be a) taught early, b) taught explicitly, and c) taught systematically [3] [8] [9] [60]. Letter-sound knowledge is needed for children to be able to decode words [8] [25]. Many researchers concur that productive letter-sound instruction strategies, using a print-to-sound reading process are key in helping children decode print [31] [35] [38].

Specific data on phonics instruction are less available [8] [9]. A main finding of the National Reading Panel's meta-analysis was that many studies on phonics instruction "did not fully describe the features included as part of phonics instruction” ([21], p. 431) The Panel members recommended that researchers further explore elements of what phonics instruction entails [21]. Others echoed Ehri's et al. sentiments, asking for clarification and clearer descriptions of phonics instruction [27] [64] [65].

\subsection{Phonemic Awareness Instruction}

Phonemic awareness instruction is used to help teach children to read [8] [31] [32]. Phonemic awareness is defined by the National Reading Panel as "the ability to focus on and manipulate phonemes in spoken words" ([8], p. 2-1). Phonemic awareness teaching approaches often do not involve print, and most often include phonemic segmentation tasks [8] [29] [31] [67]. For instance, children listen to a spoken word "cat", and then children are asked to segment the spoken word into separate speech sounds /c/, /a/, /t/ [31]. Other phonemic awareness teaching strategies include having children clap out each single letter heard in a spoken word. For instance, the teacher will speak the word "cat" and the children will clap three times, each clap representing each single sound heard [1] [8] [29]. The phonemic awareness instruction develops children's auditory skills of listening to a spoken word, then segmenting the spoken word into separate speech sounds [31] [32].

When children are able to extract and manipulate single letters within spoken words, studies show that the ability improves word decoding and overall reading ability [1] [13]. However, the National Reading Panel notes that a child will never hear a separate, distinct sound /a/ within the spoken word "cat" unless the child first understands the concept of print and that the single letter sound /a/ exists ([1] [8], pp. 2-6; 29). A similar example would be asking a child to find Waldo in a Where's Waldo book, without first showing the child who Waldo is and that Waldo exists. The National Reading Panel's caveat concurs with human learning theories that it is not experience that gives rise to learning a concept, but rather learning a concept that gives meaning to the experience [68].

The National Reading Panel researched hundreds of phonemic awareness studies and concluded phonemic awareness strategies work best with the use of letter cards so children can see print [8] [29] [69]. Children would better perform phonemic awareness listening tasks if given concrete letters to visualize and manipulate [8] [29] [69].

Recent research results suggested that rather than phonemic awareness tasks creating the ability to read, learning to read creates the ability to perform phonemic awareness tasks [38] [67] [70] [71]. Two supporting studies with deaf children were done. The children had no ability to perform phonemic awareness listening tasks, but could read [70] [71]. A study by De Graaff [38] concluded phonemic segmentation skills improved, not by performing phonemic awareness listening tasks, but by practicing reading. Kirk and Gillon [67] reported it was 
not children's phonemic awareness knowledge which was the factor in reading achievement. Instead, the use of highly structured and scaffolded spelling-patterns most impacted children's success in learning to read.

\subsection{Synthesis of Research on Letter and Letter-Sound Teaching Strategies}

Letter-sound instruction helps children learn to decode [3] [21] however, research on letter-sound instruction is a) often not explicit, b) often confusing, and c) not well defined [21] [27] [64] [65]. Three first steps are suggested and described in teaching children about letters:

- Letter naming [1] [3].

- Phonemic awareness tasks, listening to spoken words and segmenting spoken words into separate sounds [8] [31] [32] [72].

- Looking at a picture, say of a cat, verbalizing "cat" then looking at various letters and circling the correct corresponding letters, using a receptive sound-to-print process [1] [32] [66].

\subsection{Critique of Letter and Letter-Sound Research}

Letter name knowledge is not associated with growth in word decoding skills [1] [26] [73]. Despite the consistent data, letter naming continues to be a first step in teaching children to read [59]. There are no found data to support the idea that it is easier for children to look at a letter and respond with a letter name rather than the letter sound. As with the Dutch, a letter-sound response can serve as a label for a letter. Further, if a reason to teach children letter names is to help children learn letter-sounds, educators may consider following the Dutch method of teaching reading; teach letter-sound reading as a first step in learning to read. Dutch reading researcher Ludo Verhoeven explained, "Dutch children do not learn letter names; they learn letter-sounds at the moment they start to learn to read" (personal communications, March 23, 2011).

It is not clear in reading research what constitutes letter-sound knowledge or phonics instruction, and what types of prior letter-sound knowledge are needed to help children practice decoding simple words [8] [21]. Letter-sound teaching strategies often do not involve the print-to-sound process of decoding; instead the strategies use receptive sound-to-print processes [31] [35] [40] [74]. Children name letters, listen for sounds within spoken words, clap, and look at pictures, orally verbalize a picture of a cat then circle a corresponding letter of the first letter they hear, /c/. None of these strategies involve the actual print-to sound, or letter-sound reading process that would offer practice in letter decoding.

\subsection{Need for Letter-Sound Reading and Word Decoding Study}

The meta-analysis on systematic phonics instruction did not enter letter-sound knowledge into the meta-analysis database ([21], p. 401). The National Reading Panel report contains no quantitative data relating letter-sound reading to word decoding [8]. This study filled this research gap by going beyond previous traditional letter-sound knowledge studies to investigate letter-sound reading knowledge. This letter-sound reading study may indicate a need for letter-sound teaching strategies to utilize more print-to-sound teaching approaches.

\section{Research on Decoding Skills}

This section of the literature review describes studies of children's growth in decoding skills. Decoding is defined as the ability to look at print and respond with the proper sound translation, a print-to-sound process [1] [12] [38]. A single letter can be decoded by looking at the letter and orally responding with the basic sound translation [39]. Decoding ability can be fast or slow [1] [12] [36]. It is not assumed because a reader decodes a word that there is comprehension of the word; however, word decoding occurs before word comprehension occurs [8] [10].

Decoding print is important to reading because decoding print is a skill beginning readers should acquire [6] [23]. A root cause of poor reading and poor reading comprehension is lack of automatic word decoding [1] [6]-[8] [13] [22] [23]. Therefore, beginning reading instruction should have a main goal of helping children learn to decode print [1] [6] [8] [22] [23]. Research on children's growth in decoding skills is important.

\subsection{Descriptive Studies}

Some studies described word decoding growth over time [26] [39] [43] [75] [76]. Measuring growth of word 
decoding in these studies ranges from using different standardized tests given at various intervals [26] [76] and moments of measure procedures in which the researchers documented the correct words read per minute (cwpm), or correct words read per assessment session [26] [39] [43] [75] [76]. The researchers recorded accuracy of word decoding and speed of decoding [39] [43] [75] [76]. No interventions were implemented; only documentation of children's decoding skills was completed. Biemiller [39] documented speed of third graders decoding.

\subsection{Synthesis of Key Findings from Decoding Studies}

There were four key findings from the descriptive studies:

- Readers can decode connected text faster than decoding individual words [39];

- The fastest letter-sound decoders were the fastest word decoders [39];

- Children who can decode simple consonant-vowel-consonant (CVC) words in younger school years, become the better older readers [26]. Readers who learn to respond to spelling patterns are the better readers [75] [76].

These findings support the seminal writing from Fries [12] that reading acquisition is a matter of making high speed recognition and response to letters and spelling patterns.

The descriptive decoding studies also contained consistent recommendations which concur with the repeat reading studies: Children need to practice decoding in early years of schooling so decoding can evolve into an automatic skill [26] [39] [43] [75] [76].

\subsection{Critique of Decoding Studies}

With the exception of Verhoeven and Leeuwe's study [26], past studies use samples of children from second grade to adult participants [39] [43] [75] [76]. There is a lack of studies outlining the first steps children should take in order to learn to decode first words [43] [75] (Samuels et al., 1975; 1978; Schwanenflugel et al., 2006). The aforementioned studies are not transparent in describing the text the children are asked to decode. However, Verhoeven and Leeuwe [26] did detail the progression of spelling patterns the 5-year-old children decode which began with the basic CVC spelling pattern.

\subsection{Need for Letter Sound Reading and Word Decoding Study}

This new research study expanded on previous research by a) having text reading transparency, (Appendix A) b) having a sample of younger children, 4-to-6-year-old participants, and c) revisiting Biemiller's [39] design of documenting accuracy of letter-sound reading.

\section{Review of Methodological Literature}

This section of the literature review examines reading research methodology on word decoding studies offering the rationale for this research study's methodology. The sections are a) an overview of accepted reading research methodology, b) sample selection, c) moments of measure instrumentation and data collection, and d) data analysis.

\subsection{Overview of Reading Research}

Although there are some qualitative and mixed method reading research, the accepted methodology for making instructional decisions for teaching reading often come from quantitative research [8]. The National Reading Panel members are reading researchers [8]. These Panel members reviewed over 10,000 reading research studies to determine what recommendations to make to the United States Congress and the nation on beginning reading teaching strategies for children [8]. The majority of Panel members opted to review only quantitative research for the 400-page document Report of the National Reading Panel: Teaching Children to Read [8]. Qualitative studies were purposely excluded, and never considered for review [8].

Some reading researchers, like Yatvin, wanted ethnographic research and other qualitative studies included in the review of reading research for the National Reading Panel report [8]. Another reading researcher questioned the Panel members' qualitative design exclusion and called for a discussion on philosophy of science and definition of rigor in research [77]. Because advances in reading instruction and reading research are usually made 
through quantitative research, this research study used a quantitative descriptive research design.

\subsection{Sample Selection}

Some reading researchers used a representative sample of 7-year-old and older children to study beginning reading instruction [8] Few researchers select a sample of participants under 6-years-old [3]. A notable exception is Foster and Miller's [78] descriptive study. Foster and Miller used a sample of the 4-to-6-year-old beginning readers including preschool and kindergarten children. They concluded that children with poor phonics skills in prekindergarten and kindergarten correlate to poor reading achievement in the fourth grade [78]. What constituted phonics skills and letter-sound knowledge is not defined.

Hansen and Farrell [79] reported on their 12 year follow-up study that compared children in kindergarten who were taught to read with children who waited until first grade before receiving formal instruction. The kindergarten readers, regardless of their group's socioeconomic background continued to academically outperform the first grade waiters for the next 12 years [79].

\subsection{Moments of Measure Instrumentation}

The accepted procedural method to assess accurate decoding and decoding speed is called moments of measure [14] [17] [18] [20] [33] [34] [43] [55]. Moments of measure is a process of using a pencil and paper to document children's oral accuracy of word decoding, and if needed, a timing device to document speed of word decoding [15] [33] [34] [52] [55]. According to Tindal [33] the moments of measure process is a valid and reliable method of documenting children's decoding skill and decoding speed because of the simplicity of the procedure. There is notable consistency in the repeat reading research in the use of the moments of measure data collection procedure [14] [17] [18] [20] [26] [33] [34] [43] [55].

Teachers use moments of measure procedures to collect data on the accuracy of word decoding (G. Francis, personal communications, September 10, 2011). Teachers rarely use stop watches or audio recording devices, as these devices are distracting to young children (G. Francis, personal communications, September 10, 2011).

\subsection{Drawbacks of Moments of Measure Data Collection Procedure}

The moments of measure process gathers data on children's accuracy in decoding print and often their speed of decoding print [26] [33]. What the moments of measure process does not measure is reading comprehension.

This new research study used the moments of measure procedure using pencil and paper to collect data of letter-sound reading and word decoding accuracy. Checking reading comprehension was not part of this study's research question; thus, the moments of measure procedure was appropriate.

\subsection{Data Analysis}

Because reading research often employs quantitative design, analysis of data often involves use of numbers and statistical analysis. The following studies which gathered moments of measure data on accuracy of decoding used some type of analysis of variance (ANOVA) statistical procedure [15] [26] [39] [43] [52] [55].

Biemiller's [39] study with 7-to-11-year-old children gathered data to compare speed of single letter decoding with speed of word decoding. Biemiller used moments of measure data collection procedure, ANOVA, and regression analysis to examine if speed of letter decoding contributed to speed of word decoding [39].

\subsection{Critique of Past Reading Research Methodology}

Younger children are often not included in studies of beginning reading acquisition [3] [78]. It may be that the sample selection of children over 6-years-old cannot be generalized to the target population of the beginning reader. This new letter-sound reading study helped fill that void in research by using 4-to-6-year-old participants.

Previous research methodology lacks explicit descriptions of research materials and interventions [8] [21]. Few researchers of beginning reading give actual examples of the words or text the children were asked to decode. More research on beginning reading needs to be explicit on the text or words being decoded [8]. This 
study on the letter-sound reading and the relation to word decoding detailed and documented the exact text the participants attempted to decode (Appendix A; B).

\section{Seminal Publications}

This section of the literature review presents the seminal books which have impacted the evolution of reading research and reading instruction. The three seminal books are a) Becoming a Nation of Readers (The Report of the Commission on Reading), [24], b) Beginning to Read: Thinking and Learning about Print [1], and c) Report of the National Reading Panel [8].

\subsection{The Report of the Commission on Reading: Becoming a Nation of Readers}

In 1983 the National Commission of Excellence in Education published A Nation at Risk: The Imperative for Educational Reform [24]. The report A Nation at Risk noted how failure to learn to read during early years of life correlated to failure in high school and beyond [24]. Being responsive to the warning of the growing failure in teaching young children to read, Becoming a Nation of Readers was published in 1985 [24].

The 147-page book was the first document to impact beginning reading instruction on a national level [24]. The publication recommended a phonics-first reading approach echoing Jeanne Chall's book [11] Learning to Read: The Great Debate [24]. The debate between whole word reading instruction enthusiasts and phonics first reading instruction enthusiasts was somewhat put to rest.

\subsection{Marilyn Jager Adams's: Beginning to Read}

It is rare to read reading research which does not include Adams's [1] seminal work within the literature review. Produced due to congressional mandate [1], Adams's book is listed by the Institute of Scientific Information database as the most quoted seminal writing in reading research history (J. Rose, personal communication, September 10, 2011). Adams's book is a compilation and interpretation of over 50 years of quantitative reading research [1].

While the book advances the many areas of reading instruction, of primary importance to this current study is the past research on teaching children to name letters and the relationship to reading. Adams notes the decades of letter naming studies are disappointing. Learning to name letters does not help children learn to read [1]. Despite the research results, Adams advocates that letter naming be a first step in teaching children to read [1]. Dickinson and Neuman [29] quote Adams in their works advocating letter naming as a first step in learning to read. Letter naming studies have continued throughout the years [61] [62] [80].

Adams's book gives a concise description of what skillful readers do, and what young children should learn to do: visualize every single letter in every word, then instantly clump the letters into the proper spelling-to-sound translation [1]. After decades of research, Adams concludes that weaknesses in basic decoding skills of simple words are a root cause of later, lasting reading difficulties [1].

Adams's interpretation that phonemic awareness is crucial to learning to read has increased phonemic awareness teaching strategies in schools (G. Francis, personal communication, September 10, 2011). Adams is a member of the National Reading Panel; the Panel's report begins chapter one on the topic of phonemic awareness [8].

\subsection{National Institute of Child Health and Human Development: Report of the National Reading Panel}

The 400-plus-page book titled the Report of the National Reading Panel is the most recent comprehensive review of reading research literature [8]. The Panel members and contributors to the report are well known reading researchers such as Marilyn Jager Adams, Linnea Ehri and Jay Samuels [8]. The researchers gathered over 10,000 quantitative reading research studies and interpreted the results. The National Reading Panel report strongly influences how reading is taught today [8] [13].

The National Reading Panel report presents four areas needed to teach reading in the following order a) phonemic awareness, b) phonics, c) fluency, and d) comprehension. There is some dissent in the report including the way research was considered for the recommendations for teaching reading. Dr. Yatvin, also a Panel member, 
expresses panelists’ dissent in the Minority Report, claiming the National Reading Panel report contains bias [8].

\section{Literature Review Summary}

This summary of the literature review brings together the key research content noting the gaps in knowledge showing where this research study fits.

\section{Key Findings and Need for Current Study}

Reading researchers present consistent data that the main goal of reading instruction is to a) teach children how to decode, b) help children practice decoding, and c) help children practice enough so the decoding skill can become automatic [1] [8] [26] [29] [38] [43]. Seminal writings show researchers agree that letter-sound knowledge helps children decode words [1] [3] [8]. However, much research is inconsistent when defining what letter-sound knowledge is and what letter-sound instruction practices help a beginning reader develop automatic decoding skills [1] [11] [14] [20] [34] [38] [61].

Current letter-sound or phonics instruction approaches often use receptive sound-to-print activities [1] [32] [66]. The process of decoding is a productive print-to-sound process [1] [26] [32]. Therefore, a study was needed which focused on the process of decoding, decoding single letters (letter-sound reading) and decoding CVC words. A study was needed that specifically quantified differences in CVC word decoding between letter-sound-readers and non letter-sound readers who were 4-to-6-year-old participants.

\section{Methodology}

\subsection{Introduction to Methodology}

This section details the methodology used in this quantitative study. The title of the study was: Differences in mean number of consonant-vowel-consonant (CVC) words decoded between letter-sound readers and non letter-sound readers. Chapter 3 reviews the purpose of the study, the research question and hypothesis, and research design. The chapter presents descriptions of the target population, sampling, and addresses instrumentation, data collection and data analysis procedures. A final section addresses ethical issues and provides a summary.

\subsection{Purpose of Current Study}

The purpose of this study was to examine the differences in the mean number of CVC words decoded between two groups of children, letter-sound readers and non letter-sound readers. Each child was asked to read single letters to be placed in the letter-sound reading group or non letter-sound reading group. The single letters to be read, or decoded, were the 26 letters of the alphabet presented in random order (Appendix C). Each child was then asked to decode a test bank of $30 \mathrm{CVC}$ words (Appendix A) and the average values for the two groups were compared.

The membership grouping as a letter-sound reader or a non letter-sound reader followed Holcomb's [81] recommendation of grouping students by competency; a better than $60 \%$ competency achievement and less than $60 \%$ achievement. Letter-sound readers were children who independently and correctly responded with the letter-sound translation to at least 15 of the 26 lowercase letters, a $60 \%$ and above letter-sound reading competency. Non letter-sound readers were children who independently and correctly responded with the letter-sound translation to14 or fewer of the 26 lowercase letters, a below $60 \%$ letter-sound reading competency.

\subsection{Research Question and Hypotheses}

The research question was:

Is there a significant difference in mean number of CVC words decoded between letter-sound reading children and non-letter-sound-reading children?

The null hypothesis (H10) and alternative hypothesis (H1A) were:

H10: There will be no significant difference in mean number of CVC words decoded between letter-sound readers and non letter-sound readers. 
H1A: There will be a significant difference in mean number of CVC words decoded between letter-sound readers and non letter-sound readers.

The age and gender of participants were documented. A 3-way Analysis of variance (ANOVA) was used to determine how much of the difference in CVC word decoding was due to letter-sound reading after controlling for age and gender.

\section{Research Design}

Each child was asked to read single letters to be placed in the letter-sound reading group or non letter-sound reading group. Each child was then asked to decode $30 \mathrm{CVC}$ words and the average values of the two groups were compared.

\subsection{Target Population, Sampling Method, and Related Procedures}

This section describes sampling procedures and recruitment procedures.

\subsection{Target Population and Sample Size}

The target population was 4-to-6-year-old English-speaking children. The sample was selected from a preschool and day care setting. Using Statistical Analysis Software (SAS) given power of 0.8 and alpha of 0.05 , the 69 participants were sufficient to detect an $R^{2}$ of 0.19 [82], (D. Musial, personal communication, July 28, 2012; 2010; P. Flom, statistician, personal communication, June 10, 2010). In addition there were at least 25 lettersound readers and 25 non letter-sound readers. There were at least 15 participants in each age group a) 15, 4-year-olds, b) 15, 5-year-olds, c) 15, 6-year-olds, and d) 25 females and 25 males in the sample.

\subsection{Sampling Method and Setting}

The sample came from a day care and preschool setting. This setting serves 4-to-6-year-old children (N. Bing, personal communication, August 9, 2012). The day care and preschool administrator and the teacher were approached about the study. The sample was selected from this existing preschool and day care setting in which the administrator and teacher offered initial consent with signed site permission documents. This type of sampling procedure was a purposive sample selection method [83] as the sample was believed to be representative of the target population of 4-to-6-year-old English-speaking children. The sample came from a rural area in the Pacific Northwest thus may not be representative of all children.

\subsection{Recruitment}

After obtaining site permission and IRB approval, parent(s) were offered a parental consent form when picking up their children from the preschool or day care setting. The parental consent form detailed the research study. The parental consent form included an addressed, stamped envelope for the parent response. What was made clear was a) the study purpose, b) what the child would do, c) that the child could participate or not without retribution, d) there would be no harm to the child, and e) even after consent the child and parent could withdraw from the research without fear of retribution.

\subsection{Stratified Sampling}

According to Gay et al. [83] stratified sampling guarantees representation of relevant subgroups within a sample. The subgroups needed were female, male, and 4, 5 and 6-year-old children. Initially, 74 participants were accepted into the study based on signed consents. A systematic sampling selection procedure was used to select final participants.

Systematic sampling is selection of each Kth person on a list to the desired sample size [83]. After consents were returned and collected, children were further selected to be in the study based on grouping into gender, and ages 4, 5 and 6-year-old. Children in these subgroups (gender and age) were placed on a list. Every other name on the list was accepted into the study until the desired number of participants was reached. 


\subsection{Determining Group Membership}

After an initial data collection, children were placed in the subgroups of letter-sound readers and non-letter sound readers. Children were placed in the letter-sound readers group if children could respond with the basic letter-sound translation (Appendix B) to at least 15 of the 26 letters of the English alphabet. Children were placed in the non-letter-sound readers group if they could respond with the basic letter-sound translation to14 letters or fewer of the 26 letters. If there were not at least 25 children in each subgroup of letter-sound readers or non letter-sound readers, more names on the consent lists were selected into the study. Not all children with returned consents were in the study. However, almost all children with returned consents were accepted into the study.

\section{Instrumentation}

The accepted data collection method to measure the accuracy of a child's oral response to decoding print is called a moments of measures process [14] [33] [34]. The moments of measure process was used to record accuracy of single, lowercase letter-sound reading responses and CVC word decoding responses. The responses were recorded onto the data documentation sheet (Appendix C). The child's responses were documented using a pencil and paper which was familiar to children and least intrusive.

The moments of measures process often uses simple paper and pencil recording instruments and uses a one-on-one reading session involving the child and the person recording the information [14] [34]. Schools throughout the Pacific Northwest use the Read Well curriculum: In this curriculum every four weeks the moments of measures data collection process is used; a one-on-one session of a child reading words and the adult recording accuracy of the reading with a pencil (G. Francis, personal communication, June 14, 2012). In their seminal study involving over 2800 children, Verhoeven and Leeuwe [26] used the moments of measures data collection process of having children verbally decode CVC words, and researchers documenting the accuracy of the word reading. This study used the same method of documenting accuracy of a child's oral response to a single letter, and the child's oral response to CVC word decoding.

\section{Data Collection and Documentation Procedures}

At the child's regular day care or preschool site there was a small table for reading. There were a) 26 laminated, lowercase letter cards, b) 69 individual data documentation sheets (Appendix C), and c) pencil. Each data documentation sheet had the 26 lowercase letters and the CVC words already entered (Appendix C). A code for each participant was entered on each sheet. The gender and age in years and months was entered.

The participant was asked "Do you want to see what letters and words you can read?" If the child independently responded with "Yes" or nodded, and independently walked to the small reading table to sit in the chair, the child was giving assent and was shown the 26 lowercase letter cards and then shown the 30 CVC words (Appendix C). The child was asked to read the single letters and then the CVC words. The responses were documented. The child was praised and thanked.

\section{Data Collection Description}

Each participant was prompted, "See if you can say the sound each letter makes." One at a time the letter cards were shown to the child. If the child responded with the correct letter-sound translation the letter card was placed on the table towards the left. If the child responded with the incorrect letter-sound the letter card was placed on the right side of the table. A non-response was considered an incorrect letter-sound response. Long vowel sound responses, which double as the letter name, were counted as an incorrect letter-sound response. If a child named a letter the letter card was placed on the far right of the table top. Letter naming was counted as an incorrect response. As the child responded, placing the letter cards on the table provided an initial, accurate, fast documentation of letter-sound reading responses. The flow of letter-sound reading remained uninterrupted. When all 26 letter-sound reading attempts were done the data results were documented on the data collection sheet (Appendix C). A check mark next to the letter denoted correct letter-sound reading. A 0 denoted an incorrect letter-sound reading response. If a child named a letter a small $n$ was placed next to the letter on the data documentation sheet. The first $n$ on the sheet signaled a onetime corrective feedback, "Good job you know the 
letter name! Do you know what sound this letter makes?” If a child continued to name letters a small $n$ was placed by each letter named on the data documentation sheet. If a child self-corrected, for instance when seeing the letter $m$ and replied "em", then $/ \mathrm{m} /$, this was counted as a correct response. In school assessments when children self-correct, responses are counted as correct (G. Francis, personal communication, August 9, 2012).

After the letter-sound reading session the CVC word decoding occurred using a one-to-one oral assessment in which the child was presented with the 30 consonant-vowel-consonant words. Each child was asked to look at a single word and orally say the word. If the child verbalized the word correctly, the child received one point. No points were awarded for a wrong response or no response.

Unlike the letter-sound reading scenario, the participants decoded the CVC words directly from the actual data documentation sheet. The CVC words appeared as Times New Roman font, 48 points (Appendix C). A check mark next to the word denoted correct and independent decoding; a 0 denoted an incorrect response. A non-response equaled an incorrect response. After the CVC word decoding session, the participant was praised and thanked, "Good job, thank you for your participation!"

\section{Field Testing the Data Collection Instrument and Process}

According to Gay [83] it is best practice to field test some aspects of the data collection procedures in a pilot study to identify unanticipated problems. The moments of measure data collection process was field tested with four children. A needed change identified was the letter card "l" ("el") looked like the number one "1". Three of the four children reported, "That looks like a one." The letter card was corrected to look like the lower case letter "l" ("el") used in the day care setting and not the number one.

\section{Operation Alization of Variables}

This section defines the variables in the study.

\subsection{Independent Variable}

The independent variable was letter-sound reading. Letter-sound reading was defined as the ability to look at a lowercase letter and orally respond with the basic sound-translation (Appendix B).

\subsection{Letter-Sound Reading Group}

A child was be grouped as a letter-sound reader if the child could look at the 26 lowercase letters of the alphabet and correctly, orally respond with the basic sound-translation to at least 15 of the 26 letters.

\subsection{Non Letter-Sound Reading}

Non letter-sound reading was defined as looking at a single, lowercase letter and not responding with the correct basic letter-sound translation.

\subsection{Non Letter-Sound Reading Group}

A child was grouped as a non letter-sound reader if the child could look at the 26 lowercase letters of the alphabet and correctly, orally respond with the basic sound-translation to 14 or less of the 26 letters.

\subsection{Covariates}

The age and gender of participants were documented. The analysis of variance (ANOVA) differentiated if the mean number of CVC words decoded was truly related to letter-sound reading (not age or gender) after controlling for age and gender.

\subsection{Dependent Variable}

The dependent variable in the study was consonant-vowel-consonant (CVC) word decoding. In this study the dependent variable was the count of how many of the $30 \mathrm{CVC}$ words (Appendix A) were orally accurately decoded. 


\subsection{Word Decoding}

Word decoding was defined as the ability to look at print and orally respond with the proper sound translation. For instance, when a child looked at the word hen and orally said, "hen" the child was word decoding. Decoding ability can be fast or slow and is always a print-to-sound translation process [8].

\section{Data Analysis Procedures}

This study used analysis of variance (ANOVA) to quantify the relationship between letter-sound reading and word decoding mean. Assumptions of ANOVA (normality of residuals and homoscedasticity) were checked and appropriate remedies were applied if they were violated (P. Flom, personal communication, August 12, 2012). A 3-way ANOVA controlled for independent predictors of age and gender.

\section{Limitations of the Research Design}

The study design was unable to determine if participants who correctly orally responded to a CVC word were actually decoding the word or rote-recognizing the word. To decrease this limitation the 30 simple CVC words (Appendix A) offered different letters in different positions to foster a decoding rather than a rote-recognition process. The statistical analysis quantified if poor letter-sound readers had a high or low mean number of CVC words decoded which shed light on this particular limitation.

\section{Internal Validity}

Internal validity refers to the truth of an intervention or variable in a study design being responsible for the change in the dependent variable [83]. This study quantified whether letter-sound reading (independent variable) was related to CVC word decoding (dependent variable). Threats to internal validity included independent predictors not being included in the model. In this study these predictors included age and gender. To decrease this internal threat of age and gender the 3-way ANOVA was used and near-equal samples of participants in each subgroup were selected. However, because this was an observational study not an experiment, the possibility that there were other important variables that were not measured cannot be ruled out.

\section{External Validity}

External validity refers to the extent a study can extend to other groups in general [83]. Threats to external validity included the possibility that the teacher or classroom environment created the change in the dependent variable. Ideally a second research should be conducted in a second study in all new settings [84]. Another threat to external validity was that the selected setting may not be representative of all preschool and day cares.

\section{Increasing Reliability and Validity of the Study: Alpha and Power Analysis}

This quantitative study needed enough participants to have a reasonable probability of getting statistical significant results if the null hypothesis was false. According to Holcomb [81] and Gay [83] a standard in educational research is to use an alpha of 0.05 and power of 0.8 . Power analysis quantified the needed number of 50 to 60 study participants (D. Musial, personal communication, July 28, 2012; P. Flom, personal communication, April $17,2012)$. The number of independent predictors was three; letter-sound reading ability, gender, and age. A 3-way Analysis of variance (ANOVA) had a benefit of being useful with smaller sample sizes while keeping significance and power [81] [83].

\section{Overview of Findings}

\subsection{Expected Findings}

After controlling for age and gender, the expected findings of the study was letter-sound readers would have a higher mean number of CVC words decoded when compared to non-letter-sound readers. Although no found prior research had children perform letter-sound reading to directly correlate to word decoding there were studies showing letter-sound knowledge had a positive relationship to word decoding [30] [31] [35]. 
This study differentiated between the vague concept of letter-sound knowledge and the specific concept of letter-sound reading knowledge. This study isolated and examined the specific ability of decoding single letters, thus answering Ehri's et al. [21] and Burkard's [64] call for researchers to be specific about describing exactly what letter-sound knowledge means.

In this new letter-sound reading study letter-sound reading was related to word decoding. The data offer a baseline for new reading instruction methods. New reading instruction methods may initially include the activities of letter-sound reading, productive phonics, and other print-to-sound decoding activities which simulate reading.

\subsection{Other Possible Findings}

Often research produces unexpected findings [83]. A result of this research might have confirmed some prior studies, that letter-sound reading slows the word decoding process [1] [8]. If the null hypothesis had not been rejected it might guide researchers to look further into linguistic science. Linguistic reading research suggests that rather than practice in letter-sound reading (decoding single letters) it is practice in decoding highly organized spelling patterns bat, cat, fat, hat, mat, pat, rat, sat, which facilitates learning to read [8] [29]. These other possible findings should still be formally studied.

\section{Ethical Issues}

\subsection{Researcher's Position Statement}

This section of the dissertation details ethical issues related to this research study.

\subsection{Conflict of Interest Assessment}

There were no financial supports or personal interests that were a conflict of interest in conducting this letter-sound reading and word decoding study.

\subsection{Position Statement: Literacy and Health}

Nurses and other health care providers show interest in literacy [2] [85]. Poor literacy has been shown to a) evolve over time, b) cause low self-esteem, c) cause failure in school, d) correlate to entrance into the criminal justice system, e) correlate to poverty levels f) be a precursor to poor health, and g) correlate to early mortality [1] [2] [5].

Poor literacy can be viewed a chronic public health problem causing population devastation [2] [4]. In healthcare it is more effective and efficient to prevent chronic health problems, such as high blood pressure, or chronic obstructive lung disease [86]. Likewise, rather than treat poor literacy it is more efficient and effective to prevent poor literacy [1] [3] [8]. Prevention of poor literacy must occur early during ages 5 and 6-years-old [1] [3] [8] [26] [79]. Promoting early literacy promotes health.

\subsection{Ethical Issues in the Study: Working with Children}

This study was conducted with the vulnerable population of children. Thus the research process needed to meet institutional review board (IRB) approval and follow specific ethical steps. First the site administrator signed a letter of site participation consent, and then there was IRB approval. Next, when parents picked up their child from the setting parents were offered a parental consent form. This way initial parent-researcher contacts were face-to-face and questions and were answered. The parental consent form detailed the research study. Parental consent forms included the researcher-addressed, stamped envelope for the parent response. Even after parent consent, children needed to give assent to the data collection session. Children and parent(s) could withdraw from the research at any time without fear of retribution.

\subsection{Time to Read and Reflect}

The signing of consent forms was done by parent(s). Parents were afforded time after reading the consent form to be able to discuss, reflect and ask questions. The form had the researcher's phone number, e-mail address and contact was encouraged. 


\subsection{Minimal Risk}

Many 4-to-6 year old children are learning the alphabet, letter-sounds and learning to read simple words; stop, mom, their own name [31] [35]. Letters and words are all around children in preschool, school, and day care settings [3]. Many children aged 5-to-6 are in school; children are learning phonics and simple word reading skills, and are being assessed in letter recognition [59]. The moments of measure documentation of correct words decoded is used in local schools (G. Francis, personal communication, July 8, 2012) and in reading research [26]. The data collection session of letter-sound reading and CVC word decoding was similar to lessons the children receive in their preschool and school settings [14]. Children were familiar with the pencil and paper documentation.

\subsection{Ways to Minimize Possible Risk}

The data collection session involved documenting the child's response to print, single letter-sound reading and CVC word decoding. Children are usually good at naming letters, thus letter-sound reading may be new. When looking at a single letter, the child may see the letter $m$ and respond "em", rather than $/ \mathrm{m} /(\mathrm{mmmm})$. If a child initially named a letter there was praise, "You know the letter name!” "Do you know the sound the letter makes?” After an initial prompt no more prompts occurred. After the onetime corrective feedback the data collection process continued with no interruptions, no frowns, or corrections, or negative comments.

A child may not be able to decode a word the child may get frustrated. If a child remained silent, began looking around the room, squirming in the chair the data collection session would have ended. The children were always thanked and praised for participation.

The child was always given a choice to participate in the data collection session. "Do you want to read letters and words?” Even after assent the child could have ended the session at any moment without fear of retribution. Children were informed, “This session is not for your school or teacher but for my own schooling, I go to school too!” The data collection session was short lasting on average 5 minutes.

Teachers may have perceived a risk, thinking they were being evaluated. Teachers were reminded the purpose of the research was to determine if there was a difference in mean number of CVC words decoded between letter-sound reading children and non letter-sound reading children. No other risks to the community were foreseen.

\subsection{Confidentiality and Privacy}

The data were kept confidential, no setting identifiers or participant identifiers were recorded; this information was coded from the start. During data collection the child sat at a small table in the reading section of the preschool or day care setting. Other children sometimes wanted to watch. Children were reminded, "We need privacy for this part of the reading, thank you.” Other children had to go to other play areas to allow data collection privacy.

The collected data were put in a notebook, kept in a locked briefcase during travel from site then entered into a password protected computer. The parent and child had access to their own data. When entered for analysis no identifiers were present. The statistician had access to coded data only and signed a confidentiality agreement.

\section{Summary of Methodology}

This chapter presented the methods that were used in the research study on differences in mean number of CVC words decoded between letter-sound readers and non letter-sound readers. The study design, sample, data collection and analysis procedures and ethical issues were described. The next chapter presents the results obtained with the described methods.

\section{Data Analysis and Results}

\subsection{Introduction to Data Analysis}

Chapter 4 presents the description of the sample, the data collected, the statistical summary of the results, and a final detailed analysis of the statistical results. The research question was, is there a significant difference in 
mean number of consonant-vowel-consonant (CVC) words decoded between letter-sound reading children when compared to non letter-sound-reading children? The null hypothesis (H10) and alternative hypothesis (H1A) were:

H10: There will be no significant difference in mean number of CVC words decoded between letter-sound readers and non letter-sound readers.

H1A: There will be a significant difference in mean number of CVC words decoded between letter-sound readers and non letter-sound readers.

\subsection{Description of the Sample}

The sample of children who participated in the study was from one setting. All children in the study were English language speakers with English as their first language. The sample included 69 participants. There were 39 female and 30 male participants, thus $57 \%$ of the participants were girls and $43 \%$ of the participants were boys.

The average age of the participants was 5 years 2 months, or 62.81 months with a standard deviation (SD) of 9.61 months. The average age for females was 5 years and 2 months or 62.05 months. The average age for males was 5 years and 3 months, or 63.80 months. Thus the average age for girls compared to boys was nearly identical, a little over 5-years old. Table 1 shows the average age of the 4, 5 and 6-year-old participants.

\section{Summary of Results}

The research question was whether letter-sound readers decode more consonant-vowel-consonant (CVC) words than non letter-sound readers. This was investigated by testing the null hypothesis against the alternative hypothesis.

Of the 69 participants there were 34 letter-sound readers and 35 non-letter sound readers. Thus, 49\% of the participants were letter-sound readers (LSR) and 51\% of the participants were non letter-sound readers (NSLR). Letter-sound readers could respond with the basic letter-sound, or read, 15 or more of the 26 lower case letters of the alphabet. Non letter-sound readers could read 14 or fewer of the 26 letters.

From the test bank of the 30 CVC words, the letter-sound reading group's mean CVC words decoded was 17.64 words with a standard deviation $(S D)$ of 11.46 . The non letter-sound reading group's mean CVC words decoded was 0.65 words $(S D=2.40)$. The difference in mean number of CVC words decoded between the two groups was 17.35 words $(S D=8.22$ ). Using the 3-way analysis of variance (3-way ANOVA), which controlled for age and gender, the letter-sound reading group had a statistically significantly higher mean in CVC words decoded when compared to the non letter-sound reading group $\left(F_{1,65}=79.76, p<0.0001\right)$. Therefore the null hypothesis was rejected.

\section{Detailed Analysis}

Nearly equal numbers of participants in the study were letter-sound readers (49\%) and non letter-sound readers (51\%). The null hypothesis was tested with age and gender used as control variables. The 3-way ANOVA showed there was a highly significant difference in mean number of words decoded between the two groups $\left(F_{1}\right.$, $\left.{ }_{65}=79.76, p<0.0001\right)$. The letter-sound reading group had a higher mean in CVC words decoded. In addition, gender was significantly related to number of CVC words decoded $\left(F_{1,65}=12.74, p=0.0007\right)$, but age was not $\left(F_{1,65}=1.34, p=0.25\right)$. These 3-way ANOVA results are summarized in Table 2.

\subsection{Letter-Sound Reading Analysis}

Of the total 30 male participants in the study $40 \%$ were letter-sound readers. Of the total 39 female participants in the study, 56\% were letter-sound readers. Although more females than males were letter-sound readers (56.41\% versus $40.00 \%$ ) this difference was not statistically significant as shown though a chi square analysis $\left(\chi^{2}=1.83, d f=1, p=0.18\right)$. Of the total 34 letter-sound readers, 12 (35\%) were male and 22 (65\%) were female. The average age for letter-sound readers was 65.8 months or 5 years 6 months.

Of the total 35 non letter-sound readers, 18 (51\%) were male and 17 (49\%) were female. The average age of non letter-sound readers was 59.82 months, or 5 years old.

The average age for the non letter-sound readers ( 5 years) was 6 months less than the average age for the let ter-sound readers (5 years and 6 months). The difference in average age for the letter-sound readers compared to 
Table 1. Average ages of 4, 5, and 6-year-old participants.

\begin{tabular}{ccc}
\hline 4-year-old participants & 5-year-old participants & 6-year-old participants \\
\hline 4 years and 4 months: & 5 years and 4 months: & 6 years and 3 months: \\
52 months & 64 months & 75 months \\
\hline
\end{tabular}

Table 2. 3-way ANOVA results.

\begin{tabular}{cccccc}
\hline Variable & $d f$ & SS & Mean Square & $F$ Value & $\operatorname{Pr}>F$ \\
\hline Letter-sound reading & 1 & 4480.69 & 4480.69 & 79.76 & $<.0001$ \\
Gender & 1 & 715.655 & 715.65 & 12.74 & 0.0007 \\
Age & 1 & 75.30 & 75.30 & 1.34 & 0.2512 \\
\hline
\end{tabular}

non letter-sound readers was statistically significant $(t=2.74, d f=67, p<0.01)$.

\subsection{Consonant-Vowel-Consonant Word Decoding Analysis}

The mean number of CVC words decoded for all participants, whether letter-sound readers or non letter-sound readers was 9.02 words $(S D=11.83)$. The letter-sound readers had a mean of $17.64(S D=11.46)$ CVC words decoded. The non letter-sound readers had a mean of $0.65(S D=2.40)$ CVC words decoded. The estimated number of words decoded for letter-sound readers was $17.35(S D=8.22)$ words more than for non letter-sound readers, which was statistically significant $\left(F_{1,65}=79.76, p<0.0001\right)$.

\subsection{Details of Analysis of Variance}

The range in CVC word decoding was greater for letter-sound readers (LSR) than for non letter-sound readers (NLSR) as seen in Figure 1. Of the non letter-sound readers 80\% decoded 0 CVC words; there was little variance. One non letter-sound reader decoded 14 CVC words. The raw data showed this child read 12 letters, thus was grouped as a non-letter-sound reader (NLSR). The range in number of words decoded by the letter-sound readers (LSR) is denoted by the blue box on the right.

\subsection{Letter-Sound Reading, Gender, Age, and CVC Word Decoding}

Figure 2 shows among non letter-sound readers, both females (blue circles) and males (red plus signs) decoded few CVC words. The flat, horizontal blue and red lines show that age and gender made almost no difference in non letter-sound readers' ability to decode CVC words. Regardless of age and gender word decoding average remains low for non letter-sound readers. Only one non-letter-sound-reader (red plus sign) decoded more than a few CVC words. The raw data showed this child read 12 letters, and was grouped as a non-letter-sound reader. The child decoded 14 CVC words.

In the same Figure 2, letter-sound readers, both females (green Xs) and males (brown triangles) had significantly higher average in CVC words decoded when compared to non letter-sound readers. In addition, of females and males who were letter-sound readers, age slightly impacted CVC word decoding. Figure 2 shows how the two upper most green and brown lines (letter-sound readers) slope upward into higher CVC word decoding averages as age increases. This age effect on number of CVC words decoded was not statistically significant per the 3-way ANOVA results $\left(F_{1,65}=1.34, p=0.25\right)$. That age had no significant effect on number of CVC words decoded can be visualized in Figure 2 as there is a smattering of participants at all age levels decoding anywhere from zero to 30 words.

Although age did not play a statistically significant role in number of CVC words decoded, the difference in average age for the letter-sound readers compared to non letter-sound readers was statistically significant $(t=$ 2.74, $d f=67, p<0.01$ ). The differences in average age between letter-sound readers and non letter-sound read ers can be visualized in Figure 2. The non letter-sound readers (+ and zero symbols) are clustered more to the 


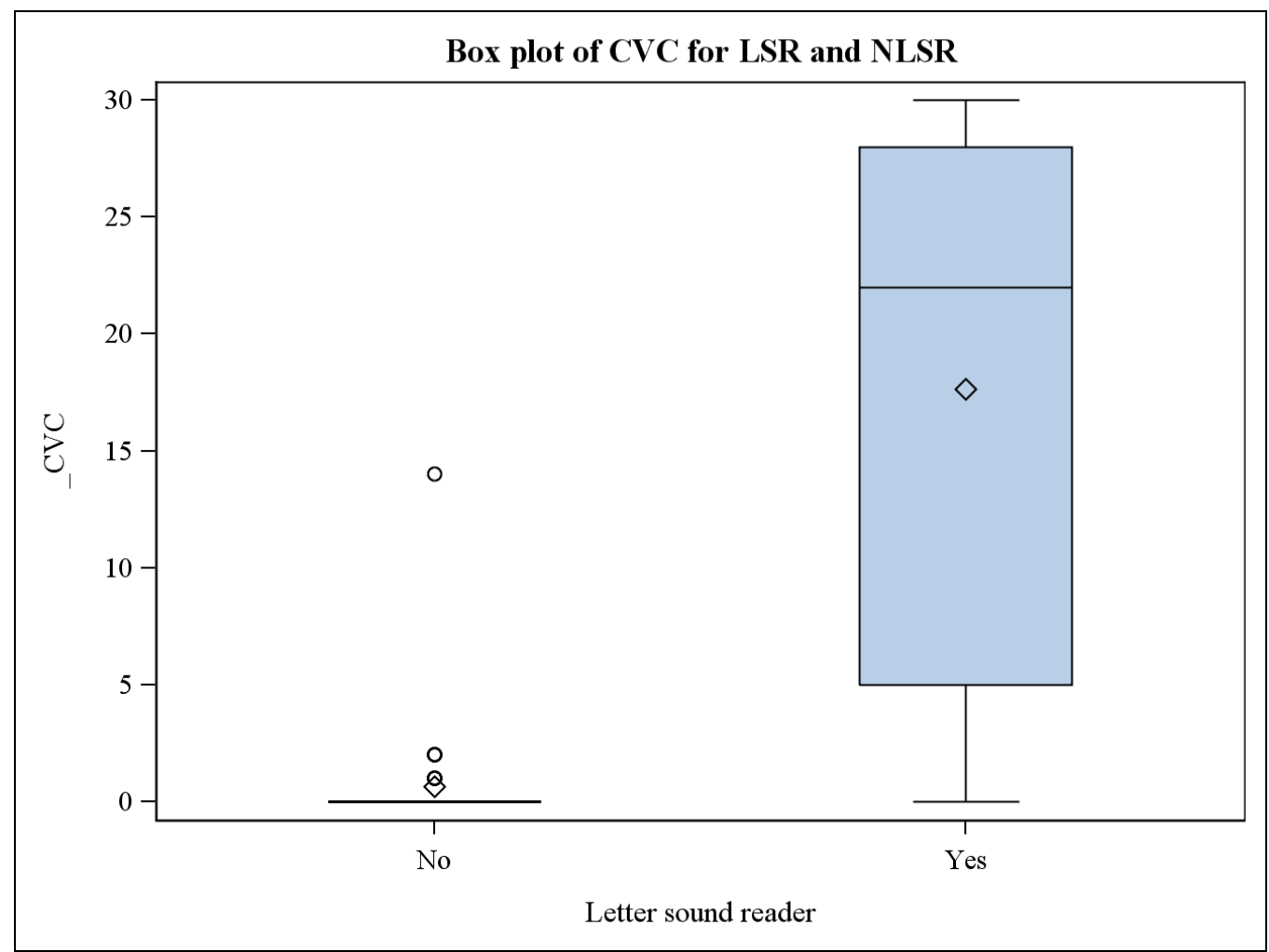

Figure 1. Variance in number of CVC words decoded for LSR and NLSR.

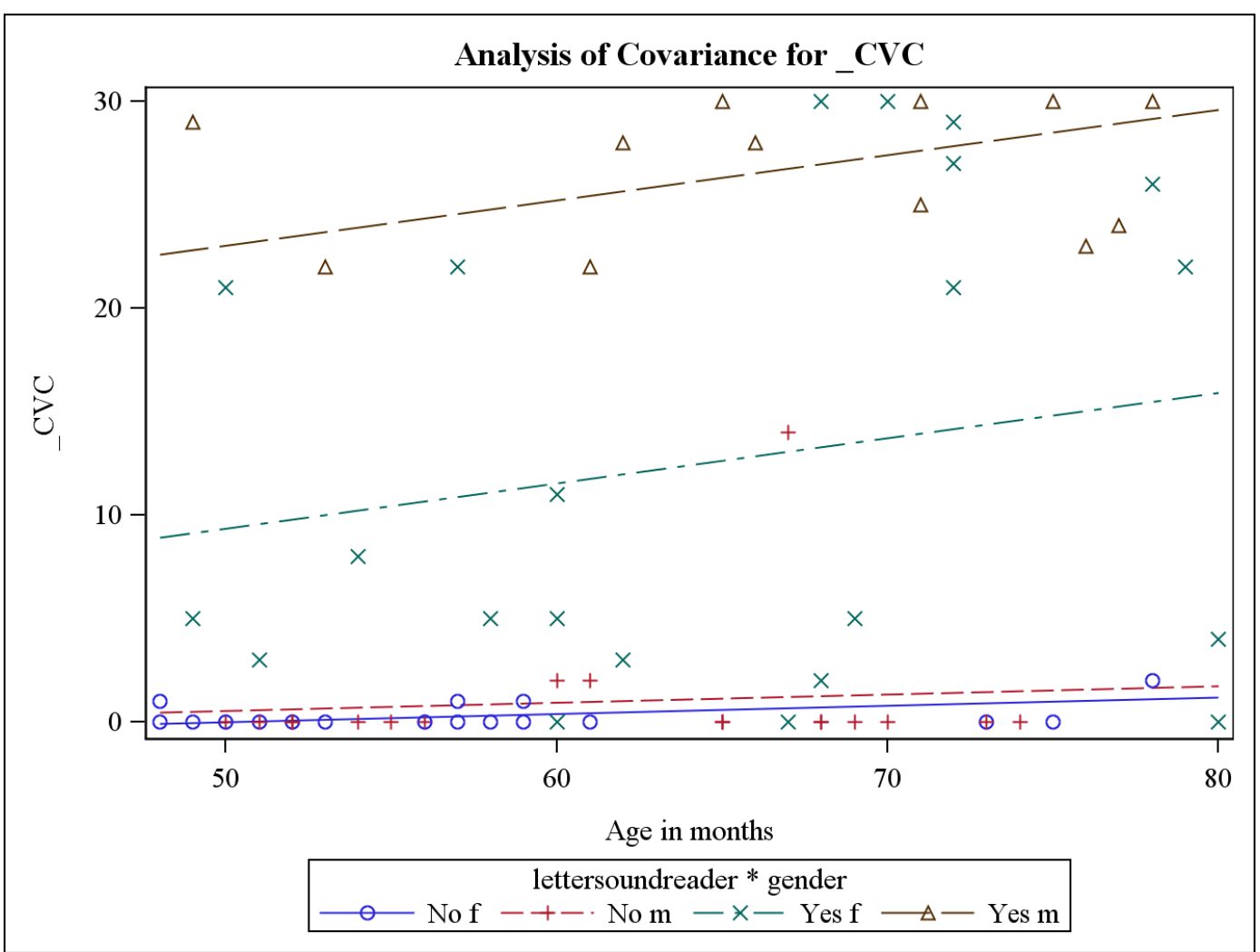

Figure 2. The 3-way ANOVA plot for number of CVC words decoded. 
left of the graph at the lower age-levels whereas the letter-sound readers are clustered at 60, 70 and 80 months. Letter-sound readers were on an average, 6 months older than non letter-sound readers. However, with the 3-way ANOVA, when controlling for age, it was letter-sound reading, not age that created the higher difference in mean CVC decoding numbers $\left(F_{1,65}=79.76, p<0.0001\right)$.

There was a gender effect on the letter-sound readers' CVC word decoding. The two upper lines have a gap between them showing letter-sound reading males (triangles) have a higher CVC word decoding average when compared to letter-sound reading females (Xs).

For non letter-sound readers, gender made no difference in CVC word decoding, there is no gap between the two lower red and blue lines in the above Figure 2. Table 3 and Table 4 present the same data numerically.

\section{Summary of Data Analysis}

There were 69 children in the research study of differences in mean number of CVC words decoded between letter-sound readers and non letter-sound readers. Of the 69 children, $57 \%$ were female and $43 \%$ were male. The average age of the participants was 62.81 months, or 5 years and 2 months. There were nearly equal numbers of letter-sound readers and non letter-sound readers.

Using a 3-way ANOVA the null hypothesis was tested against the alternative hypothesis.

H10: There will be no significant difference in mean number of CVC words decoded between letter-sound readers and non letter-sound readers.

H1A: There will be a significant difference in mean number of CVC words decoded between letter-sound readers and non letter-sound readers.

When controlling for gender and age, the 3-way ANOVA showed there was a highly significant difference in mean number of CVC words decoded between letter-sound readers (mean of 17.64) and non letter-sound readers (mean of 0.65$)$. The statistical results $\left(F_{1,65}=79.76, p<0.0001\right)$ led to a rejection of the null hypothesis.

There was a statistically significant gender effect among the letter-sound readers, with letter-sound reading males decoding more CVC words when compared to letter-sound reading females. Age did not play a statistically significant role in number of CVC words decoded. However, the difference in average age for the letter-sound readers compared to non letter-sound readers was statistically significant ( $t=2.74, d f=67, p<0.01$ ). The 3-way ANOVA showed letter-sound reading had a high effect on mean number of CVC words decoded.

Chapter 5 will further summarize and interpret the study results and offer a discussion of the results in relation to the literature. Chapter 5 will explore limitations of the study and will address the study's implications for practice and future research.

\section{Conclusions and Discussion}

\subsection{Introduction}

This final chapter restates the research problem, purpose of the study, and reviews the methodology and research

Table 3. Mean CVC words decoded: gender and letter-sound readers.

\begin{tabular}{ccc}
\hline & Non Letter-Sound Readers & Letter-Sound Readers \\
Male & $1.05(S D=3.31)$ & $25.83(S D=3.31)$ \\
Female & $0.49(S D=0.59)$ & $12.14(S D=11.30)$ \\
\hline
\end{tabular}

Table 4. Mean CVC words decoded: age and letter-sound readers.

\begin{tabular}{ccc}
\hline & Non Letter-Sound Readers & Letter-Sound Readers \\
\hline $48-59$ months & $0.15(S D=0.37)$ & $14.38(S D=10.14)$ \\
$60-71$ months & $1.80(S D=4.36)$ & $16.60(S D=12.98)$ \\
$72-80$ months & $0.40(S D=0.90)$ & $21.45(S D=10.14)$ \\
\hline
\end{tabular}


design. The major sections of the chapter a) summarize and interpret the results of the study, b) address the limitations of the study, and c) address implications for practice and recommendations for future research. The title of this study was Differences in mean number of consonant-vowel-consonant words decoded between lettersound readers and non letter-sound readers.

\subsection{Problem, Purpose, Research Question and Hypotheses}

Failure to develop basic decoding skills by first grade is predictive of lifelong poor literacy [1] [3]. Little progress has been made in discovering how young children's decoding skills develop [8] [9]. There are inconsistent data on what types of letter-sound knowledge and what types of teaching practices foster simple word decoding development [3] [8] [27] [28].

The purpose of this quantitative descriptive study was to examine the relation between letter-sound reading knowledge and mean number of consonant-vowel-consonant (CVC) words decoded in children aged 4-to-6years, controlling for age and gender. This study attempted to determine whether a letter-sound reading group had a significantly higher mean in decoding 30 CVC test bank words (Appendix A) when compared to a non letter-sound reading group.

The research question was, is there a significant difference in mean number of consonant-vowel-consonant (CVC) words decoded between letter-sound reading children when compared to non letter-sound-reading children? The null hypothesis (H10) and alternative hypothesis (H1A) were:

H10: There will be no significant difference in mean number of CVC words decoded between letter-sound readers and non letter-sound readers.

H1A: There will be a significant difference in mean number of CVC words decoded between letter-sound readers and non letter-sound readers.

\subsection{Review of Methodology}

The propose of the quantitative descriptive study was to examine the relation between letter-sound reading and CVC word decoding in English speaking children aged 4-to-6-years, controlling for age and gender. The study used 3-way Analysis of Variance (3-way-ANOVA).

Letter-sound reading data and CVC word decoding data were collected during a single session with each participant. The sessions lasted on average 5 minutes per child. Each child was shown, in random order, lowercase letter cards with one letter on each card (Appendix C). Each child was asked, "Can you tell me what sound this letter makes?” Using moments of measure process and pencil and paper, the oral responses were documented on a data documentation sheet as accurate or inaccurate (Appendix C).

A child was grouped as a letter-sound reader if the child could respond with the basic letter-sound translation (Appendix B) to at least 15 of the 26 letters of the alphabet. A child was grouped as a non letter-sound reader if the child could respond with the basic letter-sound translation to 14 letters or less of the 26 letters of the alphabet.

After the letter-sound reading attempts, each child was asked to decode 30 CVC words (Appendix A). The word decoding responses were documented as either a correct or incorrect decoding response. Specifically how many words each child accurately decoded was documented. The 3-way ANOVA was used to quantify the mean number of CVC words decoded comparing the letter-sound reading group's mean to the non letter-sound reading group's mean. The purpose of the study was to determine if there was a significant difference in mean number of CVC words decoded between the two groups.

\section{Summary of the Results}

This was a quantitative descriptive study. The research question was, is there a significant difference in mean number of consonant-vowel-consonant (CVC) words decoded between letter-sound reading children when compared to non letter-sound-reading children? When controlling for gender and age, the 3-way ANOVA showed there was a highly significant difference in mean number of CVC words decoded between letter-sound readers (mean of $17.64, S D=11.46$ ) and non letter-sound readers (mean of $0.65, S D=2.40$ ). The 3-way ANOVA showed that the difference between the groups was 17.35 words $(S D=8.22)$ and that this was a statistically significant difference after controlling for age and gender $\left(F_{1,65}=79.76, p<0.0001\right)$. These results led to 
a rejection of the null hypothesis and an acceptance of the alternate hypothesis: There was a significant difference in mean number of CVC words decoded between letter-sound readers and non letter-sound readers.

\section{Discussion of the Results in Relation to the Literature and Theories}

This section presents a discussion and interpretation of the statistical results of the study. The results are discussed in relation to the literature and theories on a) letter-sound knowledge (phonics), and b) development of word decoding.

\subsection{Statistically Significant Results}

The 3-way ANOVA results determined the differences in mean number of CVC words decoded between the two groups was significant $\left(F_{1,65}=79.76, p<0.0001\right)$. Based on these results the null hypothesis was rejected and the alternative hypothesis was accepted. However, despite the significant statistical results supporting the alternative hypothesis, caution must be taken in this quantitative descriptive study not to overgeneralize these results to include conclusions or interpretations not supported by the data. The statistical results and interpretations should be discussed in the context of prior research and accepted theories.

\subsection{Interpretation of the Results: Letter-Sound Reading Knowledge}

Letter-sound reading ability is an important foundational decoding skill that significantly increases children's CVC word decoding ability.

One significant result of the study was letter-sound readers had a higher CVC word decoding mean. Also supported by the data were non letter-sound readers were rarely able to decode simple CVC words such as tan, pig, and mop. Of the 35 non letter-sound readers, 28, or $80 \%$, decoded zero CVC words.

This data led to the interpretation that letter-sound reading knowledge is necessary for children to be able to decode the simple CVC words in the English language. Past research supports that letter-sounds, or phonics, be taught to children early and learning letter-sound units should be a first step towards decoding development [1] [13] [60]. Further, through the decades, phonics theory supports explicit phonics instruction and systematic phonics instruction [3] [8].

However, prior research on letter-sounds or phonics has often failed to describe exactly what types of phonics knowledge is needed to help children learn to decode [3] [8] [10] [21] [64]. Data from this study point to lettersound reading ability, a print-to-sound decoding process as a specific needed competency needed for CVC word decoding.

While the data from this study revealed letter-sound reading ability is an important foundational decoding skill that significantly increases children's CVC word decoding ability, the data showed letter-sound reading ability is not a sufficient condition for CVC decoding. Thus the second interpretation is:

Letter-sound reading ability is an important foundational decoding skill that significantly increases children's CVC word decoding ability; however letter-sound reading ability may not be sufficient knowledge for children to be able to decode simple CVC words.

The data showed of the letter-sound readers, 12 children decoded five words or less with three letter-sound readers unable to decode any CVC words. The range of the number of words decoded by letter-sound readers was high, spanning from zero words decoded up to 30 words decoded. This data suggest letter-sound reading knowledge alone is not enough to produce CVC word decoding success. Letter-sound reading ability is a needed foundation for CVC word decoding; however letter-sound reading ability may not be enough to produce proficient CVC word decoding.

Past research by Wanzek and Haager [87] and Pullen, Lane, Lloyd, Nowak, and Ryals [88] concluded extensive instruction in blending letter-sounds into words were key to early decoding success. Similarly, Ritchey [74] found beyond letter-sound reading knowledge, the ability to blend the letter-sounds into words was a separate and more advanced needed step in learning to decode simple words.

The National Reading Panel [8] and the National Early Literacy Panel [3] address the need for repeated practice in word decoding so decoding skill can become automatic. The theory adopted by the National Reading Panel for decoding practice is Samuels's [15] repeat reading theory [8]. The repeat reading theory postulates that when children repeat read the same brief text over and over, the decoding skill will become automatic [8] [15]. 
The data from this study support these researchers' claims that letter-sound reading knowledge alone is not enough to produce CVC word decoding success. Decoding practice, either blending letter-sounds into words and or repeat reading text may be needed to produce CVC word decoding skills.

\subsection{Interpretation of the Results: Letter-Sound Readers, Gender and CVC Decoding}

In this study, of all the letter-sound readers, males had a significantly higher CVC word decoding mean when compared to females $\left(F_{1,65}=12.74, p=0007\right)$. Gender was only important for letter-sound readers, with males' word decoding mean at 25.83, and females' decoding mean at 12.14 words.

Although statistically significant for this sample and this study, the results that letter-sound reading males read more CVC words than letter-sound reading females cannot be generalized to the population of 4-to-6-yearold children learning to read.

There was no found corresponding literature that supported the statistical results that males outperform females in beginning word decoding skills. What literature on reading acquisition did show was 10 -year-old females usually outperformed their male counterparts in reading comprehension [89] [90]; and preschool males and females possibly use different parts of their brains in learning to read processes [91]. According to Logan and Johnston [90] there is an over-arching theory, an assumption in past literature that it is easier for girls to learn to read when compared to boys. The data from this study did not support this gender-based theory.

There are inconsistencies between this study's statistically significant results and past theories on gender and reading acquisition. In this study the letter-sound reading males decoded slightly more CVC words than letter-sound reading females. The inconsistencies present an opportunity for future research with young children learning to decode. Future research is needed to duplicate this study on letter-sound reading and CVC word decoding in a different setting with more participants. A second study may either confirm or refute this study's results on gender differences of letter-sound readers decoding of CVC words.

\subsection{Interpretation of Results: Age and Letter-Sound Reading}

Although letter-sound reading ability was significantly related to the number of CVC words decoded $\left(F_{1,65}=\right.$ 79.76, $p=0.0001)$ age was not significantly related to number of CVC words decoded $\left(F_{1,65}=1.34, p=0.25\right)$. Whether a child was 4, 5 or 6-years-old had little bearing on the numbers of CVC words decoded.

However, age seemed to have a bearing on letter-sound reading ability. The average age for letter-sound readers was 65.8 months or 5 years and 6 months. The average age for non letter-sound readers was 59.82 months or 5 years and 0 months. Letter-sound readers were on an average, 6 months older than non letter-sound readers. This data was statistically significant $(t=2.74, d f=67, p<0.01)$. Letter-sound readers had a higher average age when compared to non letter-sound readers; letter-sound readers were on an average 6 months older.

The above data at face value were not surprising. Children learn, and as children get older, children gain more knowledge about letters and letter-sounds [92]. According to Callaghan and Madelaine, there is little research explaining how and why age impacts learning of young children [92].

In contrast to these researchers' statement, Maria Montessori [93] [94] spent a lifetime observing, teaching and researching how children learn. Montessori wrote about the absorbent mind of the 3-and-4-year-old children. Montessori wrote extensively that even at age five, the early years of accelerated learning capacity of young children begins to wane [93] [94].

What both Montessori [93] [94] and Callaghan and Madelaine [92] agreed upon was preschoolers have the capacity to learn literacy skills. However, the data from this study showed letter-sound readers were on an average 6 months older than the non letter-sound readers and this was a statistically significant result.

According to the National Early Literacy Panel [3] the meta-analysis of 140 studies on the effectiveness of code-focused interventions or phonics instruction was not influenced by age or developmental levels of children ([3], p. 118). The National Early Literacy Panel goes on to clarify, the findings from the meta-analysis showed there was no preexisting level of knowledge needed or skills needed before children could be taught letter-sound units [3]. In contrast to the National Early Literacy Panel's statement, Fries [12] reports, the only preexisting knowledge needed to learn to decode words is the ability to speak and understand the native language.

Often quantitative data can be further understood by revealing what data are not available [81] [83]. The data in this study contained the age of the participants, but not the grade level. Had data been collected on grade level, 
possibly there would have been insights gained on whether the letter-sound readers were attending kindergarten or first grade. Children attending kindergarten or first grade might be receiving letter-sound teaching which might explain the data result. Or the added information on grade level may have shown all participants were attending kindergarten or first grade, data that would also have added insight.

There is evidence that young children ages 4-and-5-years-old have the ability to learn letter-sound units [3] [12] [79] [92]-[94]. Regardless of this type of literature on teaching and learning for young children, the interpretation of the data in this study with this sample of participants can only be, the letter-sound readers had a significantly higher age when compared to the non letter-sound readers. There are no data available from this descriptive study to suggest the reasons for this statistical result. In addition, the data from this study may not generalize to the target population of all 4-to-6-year-old children learning to read.

\subsection{Two Main Interpretations}

The two main interpretations from this study are based on the significant statistical results that a) the letter-sound reading group had a statistically higher mean in CVC words decoded when compared to the non letter-sound reading group $\left(F_{1,65}=79.76, p<0.0001\right)$, b) of the non letter-sound readers, $80 \%$ decoded zero words, thus non letter-sound readers had little range in number of words decoded, and c) letter-sound readers had a high range in numbers of CVC words decoded (Figure 1). The two main interpretations are:

- Letter-sound reading ability is an important foundational decoding skill that significantly increases children's CVC word decoding ability.

- Letter-sound reading ability is an important foundational decoding skill that significantly increases children's CVC word decoding ability; however letter-sound reading may not be sufficient knowledge for children to be able to decode simple CVC words.

\section{Limitations}

This research study had limitations.

\subsection{Sample and Setting}

A limitation of the study was that sampling was not random. The study was small with 69 participants from one setting. The study had enough participants, letter-sound readers, non letter-sound readers, females, males and 4, 5 and 6-year-old participants to gather statistically significant results. However, higher numbers of participants improves validity of quantitative descriptive study results [83]. In addition, in this study the setting itself may have impacted the dependent variable of CVC word decoding. More participants from more sites would have improved both reliability and validity of the results. The sample of children may not offer results that generalize to the target population of all young children learning to read.

\subsection{Internal Validity}

Internal validity refers to the truth of an intervention or independent variable being responsible for the change in the dependent variable [83]; was letter-sound reading the variable responsible for the higher mean in CVC words decoded. Threats to internal validity include independent predictors such as age and gender. To decrease this internal threat of age and gender the 3-way ANOVA was used and near equal samples of participants in each age group were selected. However, this was an observational study and other important internal variables, such as developmental levels, might have impacted CVC word decoding counts.

\subsection{External Validity}

External validity refers to the extent a study can extend to other groups in general [83]. Threats to this study were the possibility that the teacher or classroom environment created the change in the CVC word decoding numbers. Because this was an observational descriptive study the possibility that there were other important variables that were not measured cannot be ruled out. Ideally a second research should be conducted in all new settings [84] [95]. Another threat to external validity is that the selected setting may not be representative of all 
preschool and day care settings.

\subsection{Study Design: The Original Research Question}

The study's research question was where the biggest limitation to the study occurred. An improved study design would have been to leave letter-sound reading as a count, a number, and then regress or compare the number of CVC words decoded to the number of letter-sounds read, controlling for age and gender. This latter described design would have allowed for examination of the nonlinear relationships between the number of letter-sounds read and the number of CVC words decoded. Thus the data analyzed would not be differences between groups, but data comparing letter-sound reading counts to counts of CVC words decoded for each participant.

Despite the study design failings, positive aspects of the study were a) a sample of young children ages 4 through 6-years was used which is needed in reading research [78], b) participants were in their normal daycare setting during data collection, and c) there were enough participant numbers and subgroups of gender, age and letter-sound reading and non letter-sound reading groups to achieve statistical significance. Further, the 3-way ANOVA helped reduce error when detecting differences between groups due to letter-sound reading by controlling for age and gender. The quantitative analysis to answer the research question had a high statistically significant value $\left(F_{1,65}=79.76, p=0.0001\right)$ showing it was not age or gender but the letter-sound reading variable which was responsible for the difference in mean CVC word decoding mean between the letter-sound readers and non letter-sound readers.

To improve on the study design four main areas of improvement should occur a) do not group children into letter-sound reading and non letter-sound reading groups, b) use more participants, at least 200, c) include more settings, and d) add grade level data.

\section{Implication of the Results for Practice}

A single quantitative descriptive study cannot provide a sound basis for changes in the beginning reading practice setting. However, with the study's statistically significant results-letter-sound readers decode significantly more CVC words than non letter-sound readers—combined with support from reading research—children need early, systematic phonics instruction [3] [8] [13] [66], the following implications for teaching young children to read should be considered.

1) In the practice setting offer children specifically designed phonics activities that rather than instill the ability to move from sound-to-print, the activities help children practice a print-to-sound, letter-sound reading (letter decoding) process.

2) Teachers and publishers of beginning reading materials need to re-examine the materials and recommended beginning reading teaching strategies and determine exactly what children are being taught to do (letter-naming, look at pictures to know a word, many sound-to-print activities?)—or-are there opportunities for print-to-sound processing. If children are not practicing the print-to-sound process, it will be difficult for the skill to become automatic.

3) In the beginning reading practice field and theory re-examine the assumption that learning to decode single letters (letter-sound reading) is a pre-reading phonics skill [3] [30]. Replace this pre-reading skill assumption with the awareness that letter-sound reading is a print-to-sound reading or decoding process, possibly a foundation for the first step to gaining automatic decoding skills. In line with this implication that letter-sound reading is not a pre-reading skill but a decoding skill, is the National Early Literacy Panel's recommendation to formally teach preschoolers to read [3].

\section{Implication for Automaticity Theory}

A main interpretation of this study was letter-sound reading is an important foundational skill which significantly increases children's CVC word decoding ability. In relation to automaticity theory letter-sound reading may be a first critical step in gaining the needed automatic decoding skill all good readers possess.

Recall, the seminal automaticity theories indicate that for children to become skillful readers a) the print-tosound decoding process must be practiced, and $b$ ) decoding must move beyond mastery to become a subconscious, automatic habit [8] [15] [22]. Further, both reading automaticity theorists, Logan [7] and LaBerge and Samuels [22] reported how skillful readers attend to every letter in every word then effortlessly group the letters 
into the proper spelling-to-sound translation. However, neither theorist addressed initial teaching strategies for children's first decoding attempts, or how children first begin to practice decoding [3].

It may be the first step toward automatic word decoding is practice in single letter-sound reading, or practice in single letter decoding. Although not specified as letter-sound reading knowledge, research by Verhoeven and Leeuwe [26] and Schwanenflugel [43] showed children who had knowledge of letter-sounds prior to word decoding practice showed gains in automaticity or automatic decoding skills. Letter-sound reading is a print-tosound decoding process. It may be that rather than teaching children an automatic letter naming response to print, the letter-sound reading response should be learned first, so this decoding response can be practiced to become automatic. Letter-sound reading might be the first step in gaining automatic decoding skills.

\section{Recommendations for Further Research}

\subsection{Duplicate Study}

A first recommendation is additional research is needed in the realms of letter-sound reading, or acquiring single letter decoding skills. A duplication of this study on a larger scale with a randomly selected sample would help to either refute or support whether letter-sound reading is a necessary skill for simple CVC word decoding.

\subsection{Researchers Must Explicitly Define Letter-Sound Knowledge}

Another recommendation is for reading researchers to clearly define phonics terms in their research; define what is meant by a) phonics, b) letter-sound knowledge, c) letter recognition, and d) alphabetic knowledge. Explicitly defining exactly what activity or skill a child is performing will help other researchers to duplicate and refine future studies. As noted by the National Reading Panel's and the National Early Literacy Panel's meta-analysis on phonics research, past researchers were often vague in describing phonics and phonics activities [3] [8].

\subsection{Examine If Letter Name Knowledge Interferes with Beginning Reading Attempts}

Letter naming knowledge is not associated with word decoding growth [1] [61] [66]. It may be that the initial letter-naming response creates a negative transfer, toward beginning reading as the initial letter-naming response must be unlearned to relearn letter-sound responses in order to accurately decode letters. However, across our nation letter naming is a recommended first step in teaching children to read [29] [59]. Therefore a third recommendation for future research is a study comparing growth of CVC word decoding skills between three groups of children.

- A group who learns letter names before learning to letter-sound read;

- A group who learns to letter-sound read before learning to name letters;

- A group who learns only to letter-sound read.

The study could discover which group has the higher growth in CVC word decoding skill, which group develops accurate and rapid CVC decoding skills at a faster rate.

\subsection{Letter-Sound Reading Teaching Strategies with Preschoolers}

A final recommendation for future research is to begin letter-sound reading interventions with young children in our preschools across our nation to discover which strategies help children practice and learn the print-to-sound process of letter sound reading more efficiently and effectively. If young children can learn to look at letters and respond with letter names; it may be young children can just as easily look at letters and respond with the basic sound translation. There is only an assumption, but no data examining if letter-naming is easier than letter naming. Recall, it is not letter naming ability but letter-sound reading, the print-to-sound process that is associated with better decoding skills [1] [3] [8].

\section{Conclusions}

This research study's question was, is there a significant difference in mean number of consonant-vowel-consonant (CVC) words decoded between letter-sound reading children when compared to non letter-sound-reading children? The 3-way ANOVA statistical results showed that when controlling for age and gender the estimated number of CVC words decoded for the letter-sound readers was 17.35 words more than the non letter-sound 
readers. The number had high statistical significance $\left(F_{1,65}=79.76, p=0.0001\right)$ thus the alternative hypothesis was accepted: There was a significant difference in mean number of CVC words decoded between letter-sound readers and non letter-sound readers. The research gap in understanding specifically what types of letter-sound knowledge or phonics knowledge helps children decode CVC words has been lessened. Letter-sound reading knowledge, a print-to-sound action and practice of decoding single letters is shown to be factor in young children's CVC word decoding abilities.

Failure to develop basic decoding skills by first grade is predictive of lifelong poor literacy [3]. Poor decoding skills in early years is linked to later poor literacy, school dropout, poverty and poor health [2] [4] [5]. Letter-sound reading or decoding single letters is an important first step towards early, proficient decoding of simple CVC words. Children in preschool, kindergarten and first grade should be given early and frequent opportunities to letter-sound read.

\section{References}

[1] Adams, M.J. (1990) Beginning to Read: Thinking and Learning about Print. MIT Press, Cambridge.

[2] Easton, P., Entwistle, V.A. and Williams, B. (2010) Health in the "Hidden Population” of People with Low Literacy. A Systematic Review of the Literature. BMC Public Health. http://dx.doi.org/10.1186/1471-2458-10-459

[3] National Institute for Literacy (2008) Developing Early Literacy: Report of the National Early Literacy Panel. National Center for Family Literacy, Jessup, 20794-1398.

[4] National Center for Education Statistics (2003) National Assessment of Adult Literacy. NAAL Website.

[5] Akers, T.A. and Lanier, M.M. (2009) Health Policy and Ethics Epidemiological Criminology: Coming Full Circle. American Journal of Public Health, 99, 397-402. http://dx.doi.org/10.2105/AJPH.2008.139808

[6] Kuhn, R.M., Schwanenflugel, P.J. and Meisinger, E.B. (2010) Aligning Theory and Assessment Fluency: Automaticity, Prosody and Definitions of Fluency. Reading Research Quarterly, 45, 230-251. http://dx.doi.org/10.1598/RRQ.45.2.4

[7] Logan, G.D. (1997) Automaticity and Reading: Perspectives from the Instance Theory of Automatization. Reading \& Writing Quarterly, 13, 123-147. http://dx.doi.org/10.1080/1057356970130203

[8] National Institute of Child Health and Human Development (2000) Report of the National Reading Panel: Teaching Children to Read; An Evidence-Based Assessment of the Scientific Research Literature on Reading and Its Implications for Reading Instruction. NIH Publication No. 00-4769. Government Printing Office of Health Publish No. 00-4754, Washington DC.

[9] Wyse, D. and Goswami, U. (2008) Synthetic Phonics and the Teaching of Reading. British Educational Research Journal, 34, 691-710. http://dx.doi.org/10.1080/01411920802268912

[10] Hovland, M., Gapp, S. and Theis, B. (2011) Look: Examining the Concept of Learning to Look at Print. Reading Improvement, 48, 128-138.

[11] Chall, J. (1967) Learning to Read: The Great Debate. McGraw Hill, New York.

[12] Fries, C.C. (1962) Linguistics and Reading. Holt, Rinehart and Winston, New York.

[13] Cassidy, J., Valadez, C.M. and Garret, S.D. (2010) Literacy Trends and Issues: A Look at the Five Pillars and the Cement That Supports Them. The Reading Teacher, 63, 644-655. http://dx.doi.org/10.1598/RT.63.8.3

[14] Deeney, T.A. (2010) One-Minute Fluency Measures: Mixed Messages in Assessment and Instruction. The Reading Teacher, 63, 440-450.

[15] Samuels, S.J. (1985) Automaticity and Repeated Reading. In: Osborn, J., Wilson, P.T. and Anderson, R.C., Eds., Reading Education: Foundations for a Literate AMERICA, Lexington Books, Lexington, 215-230.

[16] Chomsky, C. (1976) After Decoding: What? Language Arts, 53, 288-296.

[17] Kuhn, M.R. (2005) A Comparative Study of Small Group Fluency Instruction. Reading Psychology, 26, 127-146. http://dx.doi.org/10.1080/02702710590930492

[18] Therrien, W.J. and Hughes, C. (2008) Comparison of Repeated Reading and Question Generation on Student's Reading Fluency and Comprehension. Learning Disabilities: A Contemporary Journal, 6, 1-16.

[19] Eldredge, J.L. (2005) Foundations of Fluency: An Exploration. Reading Psychology, 26, 161-181. http://dx.doi.org/10.1080/02702710590930519

[20] Hicks, C.P. (2009) A Lesson on Reading Fluency Learned from the Tortoise and the Hare. The Reading Teacher, 63, 319-323. http://dx.doi.org/10.1598/RT.63.4.7

[21] Ehri, L., Nunes, S., Stahl, S. and Willows, D. (2001) Systematic Phonics Instruction Helps Students Learn to Read: 
Evidence from the National Reading Panel’s Meta-Analysis. Review of Educational Research, 71, 393-447. http://dx.doi.org/10.3102/00346543071003393

[22] LaBerge, D. and Samuels, S.J. (1974) Toward a Theory of Automatic Information Processing in Reading. Cognitive Psychology, 6, 293-323. http://dx.doi.org/10.1016/0010-0285(74)90015-2

[23] Rawson, K.A. and Middleton, E.L. (2009) Memory-Based Processing as a Mechanism of Automaticity in Text Comprehension. Journal of Experimental Psychology: Learning Memory and Cognition, 35, 353-370. http://dx.doi.org/10.1037/a0014733

[24] The Report of the Commission on Reading (1985) Becoming a Nation of Readers. The National Institute of Education, Washington DC.

[25] Comaskey, R., Savage, R. and Abrami, P. (2009) A Randomized Efficacy Study of Web-Based Synthetic and Analytic Programmes among Disadvantaged Urban Kindergarten Children. Journal of Research in Reading, 32, 92-108. http://dx.doi.org/10.1111/j.1467-9817.2008.01383.x

[26] Verhoeven, L. and Leeuwe, J.V. (2009) Modeling the Growth of Word-Decoding Skills: Evidence from Dutch. Scientific Studies of Reading, 13, 205-223. http://dx.doi.org/10.1080/10888430902851356

[27] Mesmer, A. and Griffith, P. (2005) Everybody’s Selling It—But Just What Is Explicit, Systematic Phonics Instruction? International Reading Association, 59, 366-376.

[28] Wernham, S. (2005) What Is Synthetic Phonics? Literacy Today, 8-9.

[29] Dickinson, D.K. and Neuman, S.B. (2006) Handbook of Early Literacy Research (Vol. 2). Guilford Press, New York.

[30] Gates, L. and Yale, I. (2011) A Logical Letter-Sound System in Five Phonic Generalizations. The Reading Teacher, 64, 330-339. http://dx.doi.org/10.1598/RT.64.5.3

[31] Girolametto, L., Weitzman, E. and Greenberg, J. (2012) Facilitating Emergent Literacy: Efficacy of a Model That Partners Speech-Language Pathologists and Educators. American Journal of Speech-Language Pathology, 21, 47-63. http://dx.doi.org/10.1044/1058-0360(2011/11-0002)

[32] Greaney, K. and Arrow, A. (2012) Phonological-Based Assessment and Teaching within a First Year Reading Program in New Zealand. Australian Journal of Language and Literacy, 35, 9-32.

[33] Tindal, G. (2002) Review of the Test of Word Reading Efficiency. Mental Measurements Yearbook.

[34] Valencia, S.W., Smith, T.A., Reece, A.M., Li, M., Wixson, K.K. and Newman, H. (2010) Oral Reading Fluency Assessment: Issues of Construct, Criterion, and Consequential Validity. Reading Research Quarterly, 45, 270-291. http://dx.doi.org/10.1598/RRQ.45.3.1

[35] Denton, C. and Otaiba, S. (2011) Teaching Word Identification to Students with Reading Difficulties and Disabilities. Focus on Exceptional Children, 43, 1-16.

[36] Goswami, U. (2005) Synthetic Phonics and Learning to Read: A Cross-Language Perspective. Educational Psychology in Practice, 21, 273-282. http://dx.doi.org/10.1080/02667360500344823

[37] Gray, C., Ferguson, J., Behan, S., Dunbar, C., Dunn, J. and Mitchell, D. (2007) Developing Young Readers through the Linguistic Phonics Approach. International Journal of Early Years Education, 15, 15-33. http://dx.doi.org/10.1080/09669760601106869

[38] De Graaff, S., Bosman, A.M.T., Hasselman, F. and Verhoeven, L. (2009) Benefits of Systematic Phonics Instruction. Scientific Studies of Reading, 13, 318-333. http://dx.doi.org/10.1080/10888430903001308

[39] Biemiller, A. (1977-1978) Relationship between Oral Reading Rates for Letters, Words, and Simple Text in the Development of Reading Achievement. Reading Research Quarterly, 2, 223-253. http://dx.doi.org/10.2307/747307

[40] Christensen, C. and Bowey, J. (2005) The Efficacy of Orthographic Rime, Grapheme-Phoneme Correspondence, and Implicit Phonics Approaches to Teaching Decoding Skills. Scientific Studies of Reading, 9, 327-349. http://dx.doi.org/10.1207/s1532799xssr0904_1

[41] Walton, P and Walton, L. (2002) Beginning Reading by Teaching Rime Analogy: Effects on Phonological Skills, Letter-Sound Knowledge, Working Memory, and Word-Reading Strategies. Scientific Studies of Reading, 6, 79-115. http://dx.doi.org/10.1207/s1532799xssr0904_1

[42] Samuels, S.J. (1979) The Method of Repeated Readings. The Reading Teacher, 32, 403-408.

[43] Schwanenflugel, P.J., Meisinger, E.B., Wisenbaker, J. M., Kuhn, M.R., Strauss, G.P and Morris, R.D. (2006) Becoming a Fluent and Automatic Reader in the Early Elementary School Years. Reading Research Quarterly, 41, 496-522. http://dx.doi.org/10.1598/RRQ.41.4.4

[44] Kostewicz, D. and Kubina, R. (2010) Comparison of Two Reading Fluency Methods: Repeated Readings to a Fluency Criterion and Interval Sprinting. Reading Improvement, 47, 43-63.

[45] Blessing, S.B. and Anderson, J.R. (1996) How People Learn to Skip Steps. Journal of Experimental Psychology: 
Learning, Memory and Cognition, 22, 576-598. http://dx.doi.org/10.1598/RRQ.41.4.4

[46] Samuels, S.J. and Flor, R.F. (1997) The Importance of Automaticity for Developing Expertise in Reading. The Reading \& Writing Quarterly, 13, 107-118. http://dx.doi.org/10.1080/1057356970130202

[47] Samuels, S.J., Schermer, N. and Reinking, D. (1992) Reading Fluency: Techniques for Making Decoding Automatic. In: Samuels, S.J. and Farstrup, A.E., Eds., What Research Says about Reading Instruction (2nd Edition), International Reading Association, Newark, 124-144.

[48] Faulkner, H.J. and Levy, B.A. (1999) Fluent and Nonfluent Forms of Transfer in Reading: Words and Their Message. Psychonomic Bulletin \& Review, 6, 111-116. http://dx.doi.org/10.3758/BF03210817

[49] Homan, S.P., Klesius, J.P. and Hite, C. (1993) Effects of Repeated Readings and Nonrepetitive Strategies on Students' Fluency and Comprehension. Journal of Educational Research, 87, 94-99. http://dx.doi.org/10.1080/00220671.1993.9941172

[50] Labbo, L.D. and Teale, W.H. (1990) Cross-Age Reading: A Strategy for Helping Poor Readers. The Reading Teacher, 43, 362-369.

[51] Sindelar, P.T., Monda, L.S. and O’Shea, L.J. (1990) Effects of Repeated Readings on Instructional and Mastery-Level Readers. Journal of Educational Research, 83, 220-226.

[52] Fleisher, L.S., Jenkins, J.R. and Pany, D. (1979) Effects on Poor Readers’ Comprehension of Training in Rapid Decoding. Reading Research Quarterly, 1, 30-48. http://dx.doi.org/10.2307/747430

[53] O’Shea, L.J., Sindelar, P.T. and O’Shea, D.J. (1985) The Effects of Repeated Readings and Attentional Cues on Reading Fluency and Comprehension. Journal of Reading Behavior, 17, 129-142.

[54] Schreiber, P.A. (1980) On the Acquisition of Reading Fluency. Journal of Reading Behavior, 12, 176-186.

[55] Musti-Rao, S., Hawkins, R.O. and Barkley, E.A. (2009) Effect of Repeated Readings on the Oral Readings on the Oral Reading Fluency of Urban Fourth-Grade Students: Implications for Practice. University of Cincinnati, College of Education, Criminal Justice and Human Services, 12-23. Heldref Publications, Cincinnati.

[56] McCandliss, B., Beck, I.L., Sandak, R. and Perfetti, C. (2003) Focusing Attention on Decoding for Children with Poor Reading Skills: Design and Preliminary Tests of the Word Building Intervention. Scientific Studies of Reading, 7, 75104. http://dx.doi.org/10.1207/S1532799XSSR0701_05

[57] Turnbull, K.L.P., Bowels, P.R., Skibbe, L.E., Justice, L.M. and Wiggins, A.K. (2010) Theoretical Explanations for Preschoolers' Lowercase Alphabet Knowledge. Journal of Speech, Language, and Hearing Research, 53, 1757-1768. http://dx.doi.org/10.1044/1092-4388(2010/09-0093)

[58] Piasta, S.B. and Wagner, R.K. (2010) Developing Early Literacy Skills: A Meta-Analysis of Alphabet Learning and Instruction. Reading Research Quarterly, 45, 8-38. http://dx.doi.org/10.1044/1092-4388(2010/09-0093)

[59] Bracken, B.A. and Crawford, E. (2010) Basic Concepts in Early Childhood Educational Standards: A 50-State Review. Early Childhood Education Journal, 37, 421-430. http://dx.doi.org/10.1007/s10643-009-0363-7

[60] Bowey, J. (2006) Need for Systematic Synthetic Phonics Teaching within the Early Reading Curriculum. Australian Psychologist, 41, 79-84. http://dx.doi.org/10.1080/00050060600610334

[61] De Jong, F.G. and Vrielink, L.O. (2004) Rapid Automatic Naming: Easy to Measure, Hard to Improve (Quickly). Annals of Dyslexia, 54, 65-88. http://dx.doi.org/10.1007/s11881-004-0004-1

[62] Heikkila, R., Narhi, V., Aro, M. and Ahonen, T. (2009) Rapid Automatized Naming and Learning Disabilities: Does RAN Have a Specific Connection to Reading or Not? Child Neuropsychology, 15, 343-358. http://dx.doi.org/10.1080/09297040802537653

[63] Torgerson, C., Hall, J. and Brooks, G. (2006) Synthetic or Analytic? Take Your Pick. Literacy Today, 47, 30. http://dx.doi.org/10.1111/j.1467-9345.2007.00472.x

[64] Burkard, T. (2010) So Why Can’t They Read? Literacy Today, 9-10.

[65] Cook, M., Littlefair, A. and Brooks, G. (2007) Responses to Wyse and Styles' Article, "Synthetic Phonics and the Teaching of Reading: The Debate Surrounding England's 'Rose Report'”. Literacy, 41, 169.

[66] Dilorenzo, K., Rody, C., Bucholz, J. and Brady, M. (2011) Teaching Letter-Sound Connections with Picture Mnemonics: Itchy's Alphabet and Early Decoding. Preventing School Failure, 55, 28-34. http://dx.doi.org/10.1080/10459880903286763

[67] Kirk, C. and Gillon, G.T. (2009) Integrated Morphological Awareness Intervention as a tool for Improving Literacy. Language, Speech, and Hearing Services in Schools, 40, 341-351. http://dx.doi.org/10.1044/0161-1461(2008/08-0009)

[68] Sweller, J., Kirschner, P.A. and Clark, R.E. (2007) Why Minimally Guided Teaching Techniques Do Not Work: A Reply to Commentaries. Educational Psychologist, 42, 115-121. http://dx.doi.org/10.1080/00461520701263426

[69] McCardle, P. and Chhabra, V. (2004) The Voice of Evidence in Reading Research. Paul H. Brookes Publishing, Bal- 
timore.

[70] Friedman Narr, R.A. (2006) Teaching Phonological Awareness with Deaf and Hard-of-Hearing Students. Teaching Exceptional Children, 38, 53-58.

[71] Goldin-Meadow, S. and Mayberry, R.I. (2001) How do Profoundly Deaf Children Learn to Read? Learning Disabilities Research \& Practice, 16, 222-229. The Division for Learning Disabilities of the Council for Exceptional Children. http://dx.doi.org/10.1111/0938-8982.00022

[72] Johnston, R. and Watson, J. (2004) Accelerating the Development of Reading, Spelling and Phonemic Awareness Skills in Initial Readers. Reading and Writing: An Interdisciplinary Journal, 17, 327-357. http://dx.doi.org/10.1023/B:READ.0000032666.66359.62

[73] Fletcher, J.M., Stuebing, K.K., Barth, A.E., Denton, C.A., Cirino, P.T., Francis, D.J. and Vaughn, S. (2011) Cognitive Correlates of Inadequate Response to Reading Intervention. School Psychology Review, 40, 3-22.

[74] Ritchey, K. (2008) Assessing the Letter sound Knowledge: A Comparison of Letter Sound Fluency and Nonsense Word Fluency. Council for Exceptional Children, 74, 487-506.

[75] Samuels, S.J., La Berge, D. and Bremer, C. (1978) Units of Word Recognition: Evidence for Developmental Changes. Journal of Verbal Learning and Verbal Behavior, 17, 715-720. http://dx.doi.org/10.1016/S0022-5371(78)90433-4

[76] Stanovich, K.F., Cunningham, A.E. and West, R.F. (1981) A Longitudinal Study of the Development of Automatic Recognition Skills in First Grade. Journal of Reading Behavior, 13, 58-71.

[77] Cunningham, J.W. (2001) The National Reading Panel Report. Reading Research Quarterly, 36, 326-335. http://dx.doi.org/10.1598/RRQ.36.3.5

[78] Foster, W.A. and Miller, M. (2007) Development of the Literacy Achievement Gap: A Longitudinal Study of Kindergarten through Third Grade. Language, Speech, and Hearing Services in Schools, 38, 173-181. http://dx.doi.org/10.1044/0161-1461(2007/018)

[79] Hansen, A. and Farrell, D. (1996) Research Review. The Growing Child, 14, 1-2.

[80] Bowey, J.A., McGuigan, M. and Ruschena, A. (2005) On the Association between Serial Naming Speed for Letters and Digits and Word-Reading Skill: Towards a Developmental Account. Journal of Research in Reading, 28, 400-422. http://dx.doi.org/10.1044/0161-1461(2007/018)

[81] Holcomb, E.L. (2004) Getting Excited about Data: Combining People, Passion and Proof to Maximize Student Achievement. 2nd Edition, Corwin Press, Thousand Oaks.

[82] George, D. and Mallery, P. (2010) SPSS for Windows Step by Step: A Simple Guide and Reference 17.0 Update. 10th Edition, Pearson, Boston.

[83] Gay, L.R., Mills, G.E. and Airasian, P.W. (2012) Educational Research: Competencies for Analysis and Application. 10th Edition, Pearson, Upper Saddle River.

[84] Creswell, J.W. (2009) Research Design: Qualitative, Quantitative and Mixed Methods Approaches. 3rd Edition, Sage Publications, Thousand Oaks.

[85] Haskell, D., Foorman, B. and Swank, P. (1992) Effects of Three Orthographic/Phonological Units on First-Grade Reading. Remedial and Special Education, 13, 40-49. http://dx.doi.org/10.1177/074193259201300207

[86] Allender, J.A. and Rector, C. and Warner, K.D. (2010) Community Health Nursing. 7th Edition, Lippincott, Williams \& Williams, Philadelphia.

[87] Wanzek, J. and Haager, D. (2003) Teaching Word Recognition with Blending and Analogizing: Two Strategies Are Better Than One. Council for Exceptional Children, 36, 32-38.

[88] Pullen, P., Lane, H., Lloyd, J., Nowak, R. and Ryals, J. (2005) Effects of Explicit Instruction on Decoding of Struggling First Grade Students: A Data-Based Case Study. Education and Treatment of Children, 28, 63-76.

[89] Logan, S. and Johnston, R. (2009) Gender Differences in Reading Ability and Attitudes: Examining Where These Differences Lie. Journal of Research in Reading, 32, 199-214. http://dx.doi.org/10.1111/j.1467-9817.2008.01389.x

[90] Logan, S. and Johnston, R. (2010) Investigating Gender Differences in Reading. Educational Review, 62, $175-187$. http://dx.doi.org/10.1080/00131911003637006

[91] Spironelli, C., Penolazzi, B. and Angrilli, A. (2010) Gender Differences in Reading in School-Aged Children: An Early ERP Study. Developmental Neuropsychology, 35, 357-375. http://dx.doi.org/10.1080/87565641.2010.480913

[92] Callaghan, G. and Madelaine, A. (2012) Levelling the Playing Field for Kindergarten Entry: Research Implications for Preschool Early Literacy Instruction. Australasian Journal of Early Childhood, 37, 13-23.

[93] Montessori, M. (1965) The Advanced Montessori Method (Vol. 1). (F. Simmonds, Trans.). Schocken Books, New York. 
[94] Montessori. M. (1966) The Discovery of the Child (M.A. Johnstone, Trans.). Kalakshetra Publications, Thiruvanmiyur.

[95] Lodico, G.M., Spaulding, D.T. and Voegtle, K.H. (2010) Methods in Educational Research: From Theory to Practice. 2nd Edition, Jossey-Bass, San Francisco. 


\section{Appendix A. Test Bank of 30}

\section{CONSONANT-VOWEL-CONSONANT WORDS}

tan, wag, van, bat, pal, zap

sit, pig, zip, kid, pin, hip

hen, fed, led, web, men, net

dot, mop, job, box, rob, not

fun, cup, yum, gum, rub, jug

The CVC words were presented to participants in the following order: tan, sit, hen, pig, dot, fun, cup, fed, mop, wag, zip, job, kid, van, bat, yum, box, led, pal, rob, gum, zap, pin, not, web, rub, men, hip, jug, net.

Words were presented in an order to avoid repetition of letters in beginning, middle and ending positions. To accurately decode words which contain a variety of letters, rhyming or decoding using repetition or analogy strategies will be less likely [29]. A variety of CVC words enhance the need for readers to attend visually to each letter as proficient readers do [1] [29]. Eight letters, t, n, p, g, d, l, m, and b appear in word-beginning and word-ending positions.

\section{Appendix B. Basic Letter-Sound Translations}

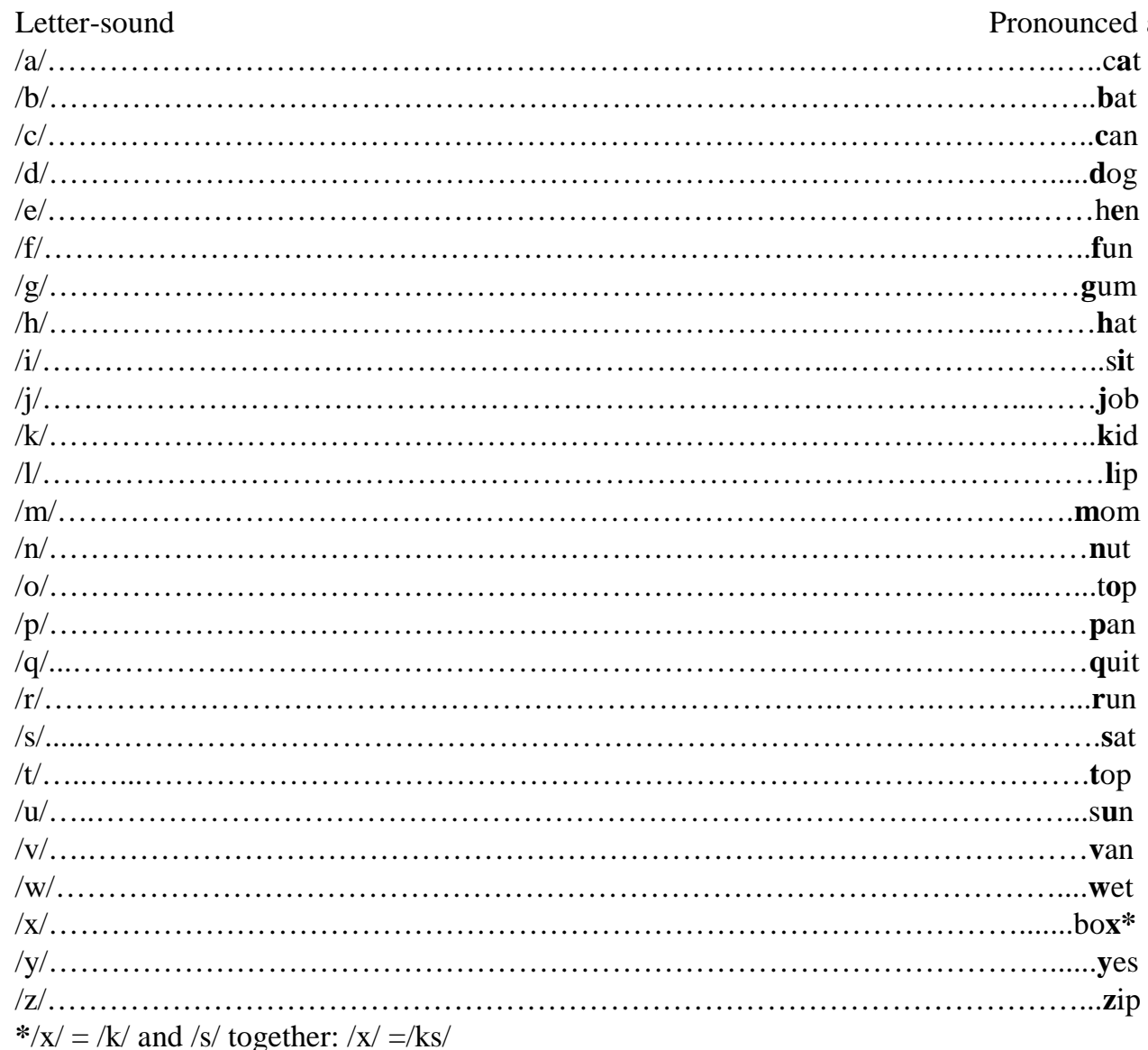

[1] 12] [30] [38] 


\section{Appendix C. Data Documentation Sheet}

Date:__ Setting Code:___Participant Code:

Gender:

Age:

Parent Present

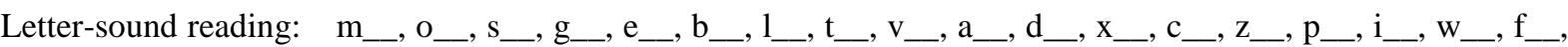
$\mathrm{n}_{\longrightarrow}, \mathrm{q}_{\ldots}, \mathrm{h}_{\ldots}, \mathrm{u}_{\ldots}, \mathrm{j}_{\ldots}, \mathrm{k}_{\ldots}, \mathrm{r}_{\ldots}, \mathrm{y}_{-}$

Corrective Feedback:

Total letter-sound reading:

Assignment to group: $\quad$ LSR*

NLSR*__ * non letter-sound reader *letter-sound reader

CVC word decoding: Total correct read:

tan, sit, hen, pig, dot, fun, cup, fed, mop, wag, zip, job, kid, van, bat, yum, box, led, pal, rob, gum, zap, pin, not, web, rub, men, hip, jug, net.

Example of actual size of lowercase letter cards: $\mathbf{m}$

Example of actual size of CVC words:

tan sit hen 